
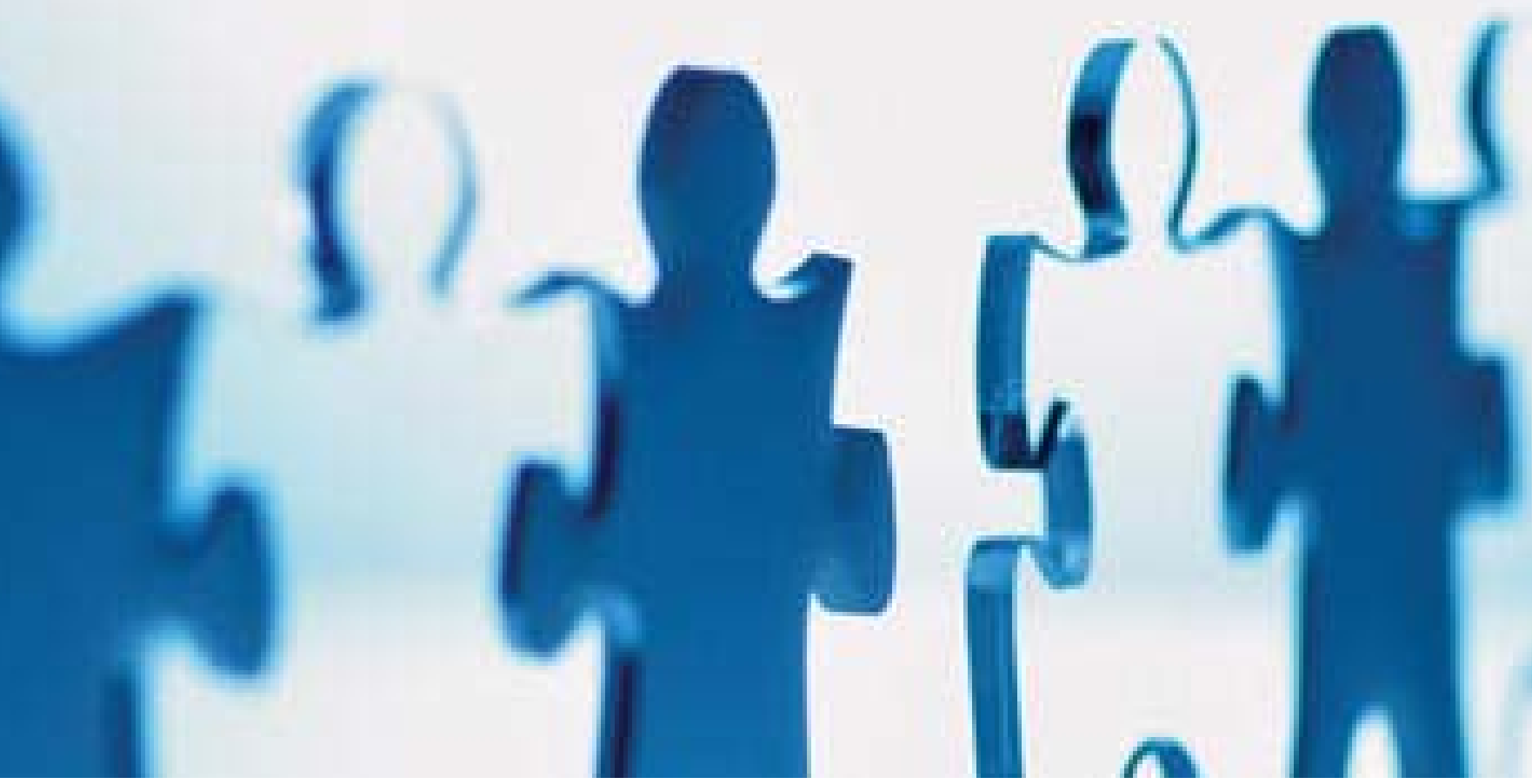

\title{
School Perspectives on Collaborative Inquiry: Lessons Learned From New York City, 2009- 2010
}

\author{
November 2010
}

Prepared by

Marian A. Robinson

with assistance from

Claire Passantino

Marsha Acerra

Lauren Bae

Katie Tiehen

Eric Pido

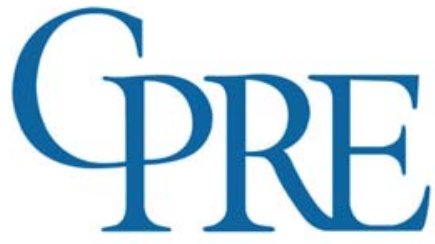

Patricia Kannapel

Mark Duffy

Connie Langland

Consortium for Policy Research in Education

Teachers College, Columbia University 
The research presented in this report was funded by a grant from The Wallace Foundation through the New York City Department of Education (contract (\#9058010) to the Consortium for Policy Research in Education (CPRE). Opinions expressed in this report are those of the author(s) and do not necessarily reflect the views of The Wallace Foundation, the New York City Department of Education, the study districts, CPRE, or its institutional members. This report has been internally reviewed by a member of CPRE's Management Committee; however, the report has not been externally reviewed.

\section{About the Consortium for Policy Research in Education (CPRE)}

Established in 1985, CPRE unites researchers from seven of the nation's leading research institutions in efforts to improve elementary and secondary education through practical research on policy, finance, school reform, and school governance. CPRE studies approaches to education reform to determine how state and local policies can promote student learning. The Consortium's member institutions are the University of Pennsylvania, Teachers College Columbia University, Harvard University, Stanford University, the University of Michigan, University of WisconsinMadison, and Northwestern University.

CPRE has opened two major centers - the Center on Continuous Instructional Improvement, which engages in research and development on tools, processes, and policies to promote the continuous improvement of instructional practice, and the Strategic Management of Human Capital in Public Education, which seeks to improve the quality of classroom instruction and student outcomes in K-12 classrooms through the strategic management of teaching and instructional leadership talent (human capital) in large, public school districts.

Learn more about CPRE and its research centers on the Web:

www.cpre.org (CPRE)

www.ccii-cpre.org (CCII)

www.smhc-cpre.org (SMHC)

Want to learn more about new and upcoming CPRE publications, project research findings, or where CPRE researchers are presenting? Sign up for CPRE's e-newsletter, In-Sites, at insites@gse.upenn.edu.

\section{CPRE Research Report \#RR-67}

Research Reports are issued by CPRE to facilitate the exchange of ideas among policymakers, practitioners, and researchers who share an interest in education policy. 


\section{Table of Contents}

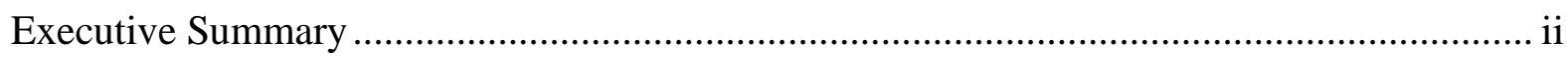

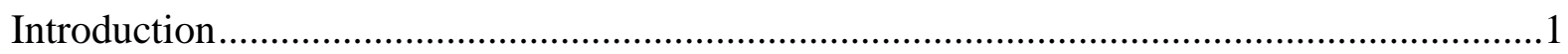

The Collaborative Inquiry Process in New York City ................................................................

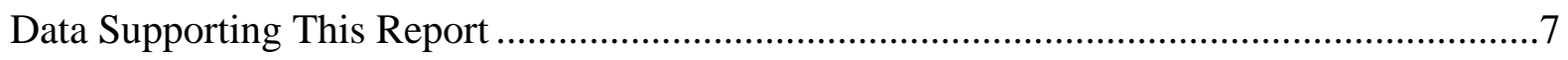

Lessons Learned in Supporting Collaborative Inquiry ............................................................9

The Distinctiveness of Inquiry Conversations ...............................................................13

Principal Leadership Style .......................................................................................16

Supporting Teacher Leadership .................................................................................21

Extending the Leadership Pipeline to the School .......................................................27

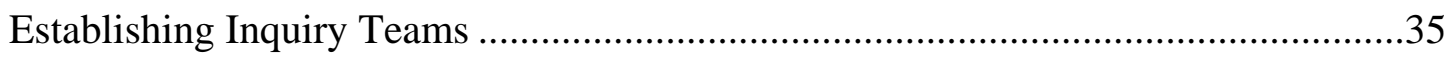

Time for Collaborative Inquiry ..............................................................................37

Teacher Use of Student Data to Inform Instruction......................................................39

Collaborative Inquiry as Ongoing Professional Development ....................................43

Connecting the Inquiry Work to School Improvement Goals ........................................51

Expectations and Policy Supports for Collaborative Inquiry .......................................55

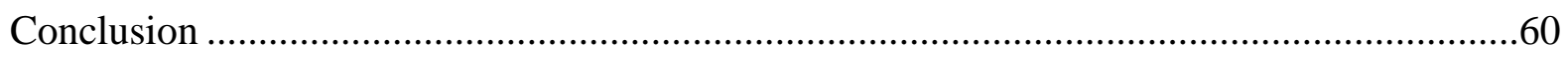

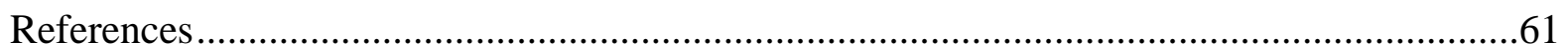

\section{Tables and Figures}

Table 1. Progression of Teacher Leadership Opportunities in Collaborative Inquiry by Principal Leadership Style .................................................................................................26

Figure 1. The Collaborative Inquiry Process ...........................................................................

Figure 2. Lessons Learned from Supporting Collaborative Inquiry, 2009-2010.......................11

Figure 3. New York City School Leadership Competencies ..................................................29 
School Perspectives on Collaborative Inquiry, 2010 


\section{Executive Summary}

The New York City Department of Education has supported collaborative inquiry as a potentially powerful process for helping administrators and teachers use student data to improve instruction and raise student achievement. Beginning with a pilot project in 2006, teams of teachers have learned to work together to diagnose the needs of students who have not been successful in their classrooms and to develop strategies to improve their learning. Collaborative inquiry sits at the heart of the Department's larger Children First initiative and aims to help educators close the achievement gap in their schools. Each year New York City schools have engaged higher proportions of faculty in the inquiry work. The goal is at least $90 \%$ participation in collaborative inquiry.

The purpose of this research report is to share lessons learned about the conditions, structures, relationships, and leadership practice that support teacher participation in inquiry. The report also presents perceived benefits of collaborative inquiry as reported by school leaders and teachers. Data come from site visits to 13 schools actively engaged in collaborative inquiry. The research team conducted 213 interviews with principals, assistant principals, instructional support staffs, and teachers participating in inquiry and 37 observations of inquiry team meetings.

The perspectives and experiences of the study schools offer lessons for supporting a high proportion of teachers in collaborative inquiry. These lessons are of interest to school leaders as well as district and state policymakers. One set of insights centers on the nature of leadership practice in support of high-quality teacher conversations about improving student learning. A principal leadership style that promotes shared decision-making enhances teacher participation in collaborative inquiry. Teachers also benefit from opportunities to cultivate their own leadership practice, which grows from their inquiry work in the classroom, during team meetings, and through actions to improve their school. Further, the inquiry process helps schools cultivate future school leaders from within their own faculty and administrative ranks.

Other insights illuminate the benefits of collaborative inquiry in developing teacher capacities to support students who are struggling. Inquiry introduces a qualitatively different conversation oriented towards enabling teachers to take action to address the immediate learning needs of students in their classroom. Importantly, the inquiry process strengthens teacher understanding and use of student assessment data to improve instructional decision-making. The collaborative inquiry process provides a source of ongoing, job-embedded professional development for teachers and informs professional development needs for the school.

A final set of lessons focuses on the conditions and supports that facilitate broad participation in collaborative inquiry. The leveraging of existing teacher groups facilitated the inquiry work more easily than creating new team structures. An essential condition is that of dedicated, protected time for teachers to work with selected inquiry students and to meet as a team. The inquiry work is more focused and productive when aligned with the school's annual improvement goals. The vision and supports provided by the Department provide enabling conditions for supporting the inquiry work in schools. 
School Perspectives on Collaborative Inquiry, 2010 


\section{Introduction}

Research continues to highlight the critical role of strong teacher learning communities in the improvement of student learning and in the capacity of schools to sustain those gains. These learning communities are groups of teachers within a given school who work collaboratively to make changes in their teaching to support particular students in their classrooms. Together they examine performance data to guide their instructional choices and reflect on the relationship between their classroom practice and student performance (McLaughlin \& Talbert, 2006).

A recent review of two decades of research has noted the positive contributions of sustained professional learning communities to improvements in teachers' instructional practice, student learning, and school development (Carroll, Fulton, \& Doerr, 2010). A number of large-scale urban initiatives in which schools have supported teacher learning communities have noted improvements in student performance (Anderson \& Togneri, 2002; Bryk et al., 2010; Center for Research on the Context of Teaching, 2002; Hightower et al., 2002). Popular data-informed decision-making processes also draw upon a collaborative inquiry process to help teachers make sense of the array of information about student learning that schools can now access (Boudett, City, \& Murnane, 2005; Mandinach \& Honey, 2008). Across these various improvement initiatives, teachers are engaged in a form of structured inquiry that guides their use of data to adjust their instruction with the goal of meeting studentspecific learning needs.
Teacher participation in evidence-oriented professional learning communities is critical to improving student performance and central to school improvement. Strong professional learning communities can promote shared decision-making across administration and teachers, which is a characteristic of leadership in effective schools (Louis et al., 2010). When supported as a school-wide process, teacher learning communities can contribute to the organizational development of the school and expand leadership practice across faculty (Copland, 2003; Harris \& Muijs, 2004). Through professional dialogue and action, teacher inquiry can help school leaders cultivate a culture of responsibility for student performance in their school. It can also stimulate and support leadership practice among teachers (Harris \& Muijs, 2004; York-Barr \& Duke, 2004).

Since 2006, the New York City Department of Education has been developing a process of collaborative inquiry to help city schools make better use of student data to improve instruction and learning and, ultimately, close the achievement gap. Through collaborative inquiry, teams of teachers work together over the course of the school year to diagnose the needs of students who have not been successful in their classrooms and to develop effective strategies to meet their learning needs. These students are among the lowest performing and meeting their learning needs constitutes the achievement gap that educators seek to close. Teacher teams also use inquiry to address the learning needs of higher performing students. As a school-wide process, collaborative inquiry broadly aims to improve the instructional capacity of teachers and strengthen the decision-making that supports student improvement. 
This research report offers insight into the experience of New York City administrators and teachers who have been engaged in collaborative inquiry. It presents a set of lessons learned that call attention to the conditions, structures, relationships, and leadership practices that positively support teacher participation. It also presents the perceived benefits of collaborative inquiry as reported by school leaders and teachers. Data supporting this report come from interviews with principals, assistant principals, instructional support staff, and teachers from 13 city schools. These educators were active participants in over 80 teams engaged in collaborative inquiry. 


\section{The Collaborative Inquiry Process in New York City}

The collaborative inquiry process was rolled out in New York City schools in 2007 after being piloted the year prior in 332 Empowerment Zone schools. Since then, the Department has asked schools to engage a higher proportion of faculty in the inquiry work each year, from a small team of educators in 2007-08, to one-third of faculty in 2008-09, to two-thirds of faculty in 200910 . The ultimate goal is at least $90 \%$ teacher participation in inquiry.

The Department provides both guidance and resources to schools to support broad teacher engagement in collaborative inquiry. This effort includes guidance to school leaders about the configuration and launch of inquiry within the school and the key features and decision points of the inquiry process. It also includes a portfolio of resources and assistance to support the use of student performance data throughout the collaborative inquiry process.

The Collaborative Inquiry Process. The key processes supporting school-wide engagement in collaborative inquiry are presented in Figure 1. These include the annual launch of the inquiry work by the principal, the instructional inquiry cycle led by teacher teams, and a school-wide inquiry process in which the insights of teacher teams guide improvements to key systems of the school.

In the set-up phase early in the school year, each school engages in a self-assessment based on student performance data and then sets appropriate goals. To launch the inquiry work for the year, the principal engages faculty and administration in a discussion of the over-arching goals, and teachers become familiar with the goal or goals that will guide their team's inquiry work. Drawing upon existing groups and structures within the school, school leaders establish teacher teams in which each member shares responsibility for a common group of students in the school, such as a grade level or subject area. In collaboration with teachers, school leaders identify a teacher on each team to be its facilitator or leader.

Each teacher team then begins the instructional inquiry cycle. The goal of this collaboration is to identify and successfully address the learning needs of students in their charge. Teachers begin the process by examining performance data, student work, and other background information to identify a struggling student population with a common learning need. To help focus their work, teachers select a small group of "inquiry students" from the population to work closely with throughout the process. Teachers examine existing conditions of teaching and learning across classrooms and in the broader school to identify weaknesses in current practice. This effort may include a review of student work and curricular materials as well as visits to the classrooms of fellow teachers to observe the enacted curriculum and how students are responding. With this background knowledge, the teacher team identifies an instructional strategy to test, drawing upon expertise from within the school, education research, external partners, or other colleagues. After setting performance goals to judge the effectiveness of the strategy, teams test the strategy with their inquiry students and monitor their learning progress using common assessments. Based on student progress, the team revises the instructional strategy or begins a new cycle of inquiry focused on a different learning need. Ideally, each teacher team will conduct multiple 
Figure 1.

The Collaborative Inquiry Process

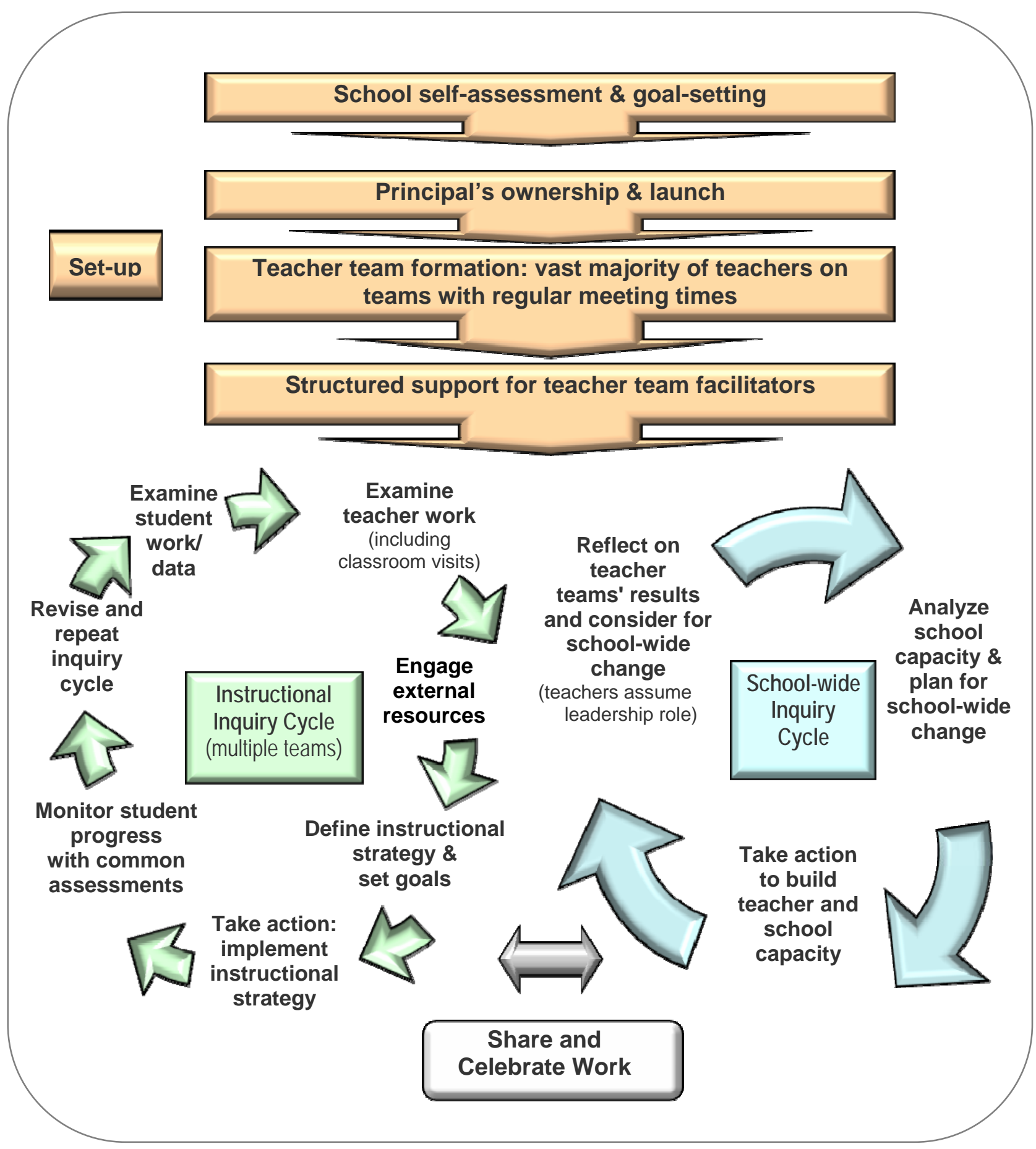

Source: New York City Department of Education, n.d. 
cycles of inquiry over the course of the school year.

The school-wide inquiry cycle is conducted by a "core team" of administrators and teacher representatives drawn from each inquiry team in the building. The goal of the core team is to reflect on the results obtained by the teacher teams and their implications for strengthening the broader systems of the school. These systems may include the school's current organizational structure, official curriculum, staff capacity, and resource allocation. The goal is to ensure that effective strategies become used schoolwide, as appropriate, and that the conditions of teaching and learning in the building support their use. Actions to build teacher capacity may include targeted professional development and access to appropriate material resources. Actions to build school capacity may include official adjustments to curricular materials and expectations for the use of specific instructional strategies or assessment practices. In the school-wide inquiry cycle, teachers would assume a greater leadership role in shaping the policy decisions that aim to improve the performance of the school.

\section{Expectations and Policy Supports.}

Collaborative inquiry is a key component of the Department's larger restructuring initiative, known as Children First, and embodies its three core principles of leadership, empowerment, and accountability. Within these principles is the philosophy that accountability is a reciprocal process, that the Department is responsible for providing the necessary supports to help schools achieve the results for which they are being held accountable.

To guide and support the inquiry work, the Department communicates expectations for school performance and provides supports to assist schools with implementation. A set of accountability tools establishes student performance expectations and provides feedback to individual schools. The annual Progress Report helps a school identify student subpopulations who have not yet reached proficiency in the different content areas. The Quality Review focuses school leader attention on the quality of internal systems for managing data and their connections to systems supporting instruction and resource allocations. The Department has linked eight of the 20 indicators of the Quality Review to the work of teacher teams engaged in collaborative inquiry. Principals are held accountable for their school's annual progress in meeting performance targets. In exchange, principals have gained more control over the school budget and hiring of staff. In addition, inquiry is a required component of a principal's Comprehensive Education Plan, an annual strategy report detailing plans for school improvement. The success of teacher teams is also a factor in the Principal Performance Review.

The Department also provides schools with technology and data resources to support the inquiry work. Teachers now have access to diagnostic and monitoring tools that provide timely information about the performance of their students. These include a portfolio of formative assessments that teachers can customize. Teachers also have direct access to the Achievement Reporting and Innovation System (ARIS), a comprehensive online data system that integrates student performance, academic records, demographical information, and other historical data to help teachers identify struggling students and examine patterns in their performance. ARIS also includes a knowledge-sharing platform called ARIS Inquiry Spaces to facilitate exchanges within and across inquiry teams. Teachers and 
other educators can access a searchable library of curricular and instructional materials aligned with state standards.

Finally, schools have access to professional support. Schools identify a part-time Data Specialist who is responsible for supporting teacher and administrator use of ARIS. In addition, schools have access to external support through their network team. Either a Senior Achievement and Technology Integration Facilitator (SATIF) or another network team member who is an experienced educator/administrator with intensive training in the inquiry process provides support to teacher teams in network schools. In concert, these initiatives and supports aim to provide school leaders and teachers with the authority and resources needed to build internal capacity to close achievement gaps in their building.

Anticipated Outcomes. The inquiry process has the potential to stimulate a number of positive outcomes. The ultimate goal of teacher inquiry is improved achievement for all students. When supported school-wide, the inquiry work helps principals establish and strengthen teacher professional learning communities across the school. It provides teachers a process for improving their instruction to meet the particular learning needs of students in their classroom. It helps teachers use evidence of student learning to inform their instructional choices. Schoolwide participation in collaborative inquiry has the potential to cultivate a culture of responsibility among teachers for improving student performance. Sustained over time, inquiry has the potential to improve the instructional capacity of teachers and to strengthen the organizational systems that support teaching and learning in the school. 


\section{Data Supporting This Report}

Data supporting this report come from a purposeful sample of 13 elementary and secondary schools. These schools had participated in an earlier study of the initial introduction of the inquiry process to city schools (Robinson et al., 2008). We invited schools that were engaging a high proportion of faculty in collaborative inquiry in 2009-10 and were serving a high to moderate proportion of students who were struggling. Study schools present diverse contexts for the implementation of collaborative inquiry in terms of school level and size, teacher professional culture, the proportion of students from poor homes or receiving special services, and progress in improving student achievement, particularly for student subpopulations. Three quarters of study schools were rated proficient or welldeveloped on their recent Quality Reviews. Regardless of their accountability standing, all administrators and teachers reported feeling continuous pressure to improve student performance.

Data supporting this study were collected in spring 2010 during site visits to the 13 study schools. The research team conducted a total of 213 interviews, which included principals, assistant principals, instructional support staffs, and teachers who were actively engaged in the inquiry work. This typically included all core inquiry members and at least two teachers from each inquiry team in the school. Interviews with administration focused on understanding school context and professional relations and the school approach to inquiry and connections to improvement efforts. We were also interested in administrator views on teacher engagement in the inquiry work and outcomes to date, leadership practice they associated with inquiry, and the potential of inquiry as a professional development process. Interviews with teachers focused on understanding the goals, process, and results of the inquiry work; available resources and sources of support; and teacher efforts to share their inquiry findings and to contribute to school improvement. We were also interested in teachers' general views on leadership practice in the building; the opportunities for teacher leadership through the inquiry work, and teacher views on the value of the inquiry process for themselves and for the school.

The research team also conducted 37 observations of both core and teacher inquiry meetings, which lasted 40-90 minutes each. Observations focused on team dynamics, the focus of inquiry conversations, and use of student data. During interviews, we also collected 140 material artifacts that teachers identified as important to their inquiry work or team conversations. These included inquiry process templates, a variety of customized data reports, sample instructional strategies, teacher developed assessments, student work examples, and school newsletters.

To compare and contrast school approaches to and experiences with inquiry, we created a descriptive profile of each school that drew upon all interviews and inquiry team observations. All data were coded using ATLAS.ti data management software which aligned with the profile framework. Profiles described key features of the school context and professional culture; the focus, configuration, and roll-out of inquiry in the school; views on leadership practice associated with inquiry; reported growth in teacher capacity; the contributions of inquiry to school development; and factors influencing implementation. A cross-school 
analysis of the patterns of implementation, leadership practice, and perceived benefits of collaborative inquiry provide a basis for the lessons learned in this report. To protect the confidentiality of participants, we used the female gender to report all data. 


\section{Lessons Learned in Supporting Collaborative Inquiry}

The purpose of this report is to share lessons learned from the implementation of collaborative inquiry in New York City Schools. A broad goal of the study was to examine how schools were responding to the Chancellor's expectation that a high proportion of faculty participate in collaborative inquiry. Of particular interest was understanding effective school approaches to implementing collaborative inquiry at scale, new patterns of distributed decision-making emerging in schools, new opportunities for leadership practice across administrators and teachers, and growth in teacher capacity to address specific student learning needs.

Almost all study schools were in their third year of implementation during the 2009-10 school year. During this year, schools supported a broad expansion of inquiry from one or two inquiry teams in prior years to the participation of $80-100 \%$ of faculty, according to principals. Elementary schools were supporting 6-8 teacher inquiry teams and secondary schools were supporting 5 to $30+$ inquiry teams - with the latter allowing teachers to join multiple teams. Almost all schools had established a core inquiry team that took a school-wide view on the inquiry work, but the purpose varied. The principals of study schools were positive about the promotion of collaborative inquiry as a Department initiative, and many were enthusiastic.

This sample of study schools varied in their level of implementation. Five of the 13 schools had reached a well-developed or advanced stage of inquiry. These schools were led by principals who employed a participatory style of leadership that supported shared decision-making across administration and teachers. All of these schools supported participation by at least $90 \%$ of faculty. Teachers reported a high level of engagement and support for the inquiry work and their teams. These schools had a strong professional culture in which teachers engaged in conversations about their practice, although most informally, and in which positive, productive relationships existed between teachers and administration. Teachers reported benefiting from inquiry at an individual and team level, and felt their capacities to use student data to inform their instruction and ability to differentiate their instruction were expanding. Variation in implementation across teams in each school was relatively low. Almost all reported completing two or more cycles of inquiry; they reported growth in the learning of inquiry students and had identified strategies that had proven effective. The core inquiry team was an active decision-making body and had identified at least one, if not more, adjustments to the school through the inquiry work. Teachers saw the inquiry work as strongly connected to their school's larger performance goals and to their work with a small group of inquiry students in their classrooms. Teachers also reported new or expanded opportunities for teacher leadership that stretched from the classroom to the school level.

Four of the 13 study schools had reached an emerging stage of inquiry. These were schools where the professional culture was underdeveloped, such that teachers had no established routines for collegial exchange about their classroom practice or a shared commitment to joint work. Principal and teacher relationships were generally positive in these schools, but there was a history of tension between teachers and most assistant 
principals. The schools were led by principals who employed a delegative style of leadership. To initiate collaborative inquiry in this context, principals pushed control of the inquiry work to teacher teams to encourage teachers to build professional relationships and to stimulate a collective ownership of student learning. All of these schools supported the goal of at least $90 \%$ teacher participation in inquiry, and teachers reported high to moderate support for and engagement in inquiry. Teachers reported benefiting from inquiry at an individual and team level. They felt their capacity to use student data to inform their instruction had expanded. The greatest benefit to them, not surprisingly, came from the opportunity to forge positive, professional relationships with other teachers through their inquiry conversations, which focused on improving their collective classroom practice. Variation across teacher inquiry teams was moderate to high, largely due to the newness of the process and a history of weak teacher relations. Many teams were able to complete one or two cycles of inquiry; teachers reported some growth among the inquiry students. In this context, the core inquiry team focused on helping teacher teams understand key steps in the inquiry process, develop routines of data analysis, and examine the relationship between instruction and evidence of student learning. Teachers reported some expanded opportunities for teacher leadership that extended from their classroom to their teacher team, but not as much at the school level.

Four of the 13 study schools remained at a beginning stage of inquiry. These schools were led by principals who employed two contrasting leadership styles, either a delegative style that left teachers on their own to implement inquiry or an authoritative style that tightly controlled teacher relations and the inquiry work. Although these schools encouraged $80-100 \%$ faculty participation in inquiry, teachers reported low levels of engagement. In two schools, this was due to the lack of dedicated and protected time for teacher collaboration. In the other two schools, low engagement was due to insufficient guidance or a heavyhanded control from administration over inquiry team conversations. The professional culture of these schools was highly varied, ranging from a family-like but hands-off relationship between administration and teachers to a more unilateral relationship where administration heavily supervised teacher lesson planning and instruction. Teachers reported limited benefits from collaborative inquiry, typically only through their work with inquiry students. In two schools, teachers did not have dedicated or protected time to meet as an inquiry team; in others, time was restricted due to heavy administrator oversight. The core inquiry team was not well established and its purpose was unclear in these four schools. Most teachers reported no authentic opportunities for teacher leadership beyond their own initiative to support inquiry students in their classrooms.

These study schools offer a number of lessons learned about supporting a high proportion of teachers in collaborative inquiry (see Figure 2). One set of insights centers on the nature of leadership practice that supports teacher inquiry conversations and emerges through the work itself. A principal leadership style of shared decisionmaking enhanced teacher participation and ownership of collaborative inquiry. Teachers also benefited from new or expanded opportunities to cultivate their leadership practice, which emerged within their own classrooms as well as from conversations with inquiry team members and their schoollevel contributions. Furthermore, there is evidence the inquiry work can help schools 
Figure 2:

Lessons Learned from Supporting Collaborative Inquiry, 2009-2010

- Inquiry stimulates a qualitatively different conversation about improving teaching and learning in the school.

- Principal leadership that supports shared decision-making enhances teacher participation and ownership of collaborative inquiry.

- Inquiry work creates powerful opportunities for teacher leadership.

- The inquiry process helps create a pipeline of leadership from within the school.

- Leveraging existing teacher groups facilitates inquiry work more easily than implementing new team structures.

- Dedicated, protected time for collaborative inquiry is essential.

- Inquiry strengthens teacher understanding and use of student assessments and performance data to improve their instructional decision-making.

- Collaborative inquiry is an effective form of on-the-job professional development for teachers and can lead to the identification of schoolwide professional development needs.

- Collaborative inquiry work is more focused and productive for teachers when aligned with school improvement goals, particularly when teachers are engaged in the goal-setting process.

- Sustaining a cohesive central vision for student achievement and aligned policy supports is critical to deepening the inquiry work. 
create a pipeline of future leaders from within their own faculty and administrative ranks.

Another set of insights is drawn from the reported benefits of collaborative inquiry in developing teacher capacity to support students who are struggling. Inquiry was seen to stimulate a qualitatively different conversation about teaching and learning than was underway in most study schools. Teachers reported that the inquiry process strengthened their understanding and use of student assessment and performance data to improve their instructional decision-making. In study schools, the collaborative inquiry process was an effective form of on-the-job professional development that enhanced teachers' classroom practice and informed school-wide training needs.

A final set of lessons focuses on the conditions and supports that facilitate teacher inquiry. Principals found that leveraging existing teacher groups facilitated the inquiry work more easily than implementing new team structures. An essential condition was identifying dedicated, protected time for collaborative inquiry, including time for teachers to work with inquiry students and time to meet as a team. The inquiry work was most focused and productive when aligned with the school's improvement goals, especially when teachers were engaged in a goalsetting process at the start of the school year. The vision and supports from the Department provided enabling conditions and resources that teachers and administrators considered critical to the inquiry work.
In the next section each lesson learned is presented, drawing upon the experiences of these 13 schools. It is important to note that this was the first year in which collaborative inquiry was supported virtually school-wide in these schools. The insights garnered from interviews and observations can inform the decision-making in schools seeking to initiate collaborative inquiry or strengthen the inquiry work already underway. 


\section{The Distinctiveness of Inquiry Conversations}

\section{Inquiry stimulates a qualitatively different conversation about improving teaching and learning in the school.}

Collaborative inquiry positions teacher teams as the primary investigators of significant problems of teaching and learning in their school. When compared with current faculty, grade level, or department meetings, the collaborative inquiry process supports a qualitatively different type of professional discussion across study schools. This difference stems, in part, from the very purpose of inquiry, which offers teachers a process for identifying effective strategies to meet the needs of students who have not been successful. One teacher explained the difference this way:

Faculty conference meetings are about logistics and when things are due, citywide training as far as HIV practices, child abuse, those type of things, and what to include in the report card. Inquiry is writing SMART goals, how do we collect our data, what strategies are we using, which ones are working with what particular group of children, "I tried it this way," for example. So, it is very specific.

The distinctiveness of inquiry is important because it brings into high relief the key dimensions of the process that make it effective. From the perspective of teachers, collaborative inquiry discussions differ from other professional conversations in their schools in four important ways. Specifically, inquiry is a new and valued opportunity for teachers because

- It provides a structure for teacher conversation and enabled teachers to focus on the immediate problems of teaching and learning in their classrooms;

- It helps teachers use data in their instructional decision-making;

- It emphasizes teacher participation; and

- It enables teachers to establish new working relationships with others struggling with similar problems of student learning.

Teachers value inquiry because it provides them with a structured process that centers on the immediate problems of teaching and learning in their classrooms. One teacher explained the difference: "Inquiry meetings are more focused and goal-oriented than other meetings I attend." In interviews, teachers attributed this difference to the "scaled down" nature of inquiry conversations, which focused on specific students who were struggling with particular concepts and instructional strategies. This focus contrasted with broader class and grade-level conversations. In schools with a strong professional culture, the inquiry process authorized and formalized dialogue among teachers, which previously occurred in the hallway and during lunch. For teachers, the new dedicated time helped conversations about instruction become focused and consistent, and ultimately, more productive. In schools where professional relations were weak and classroom practice remained privatized, 
teachers valued inquiry's structured process because it helped teachers establish a culture of conversation about their instructional choices.

\section{Teachers value the inquiry process because it helps them incorporate student data into their instructional decisions.} Teachers viewed the emphasis on data as another unique feature of inquiry. During inquiry team meetings, teachers reported gathering and organizing data to diagnose student learning needs and to monitor student progress in an ongoing manner. Teachers also reported an emphasis on compiling and analyzing student data from multiple sources, such as classroom behavior, student work and formative assessments, to diagnose a learning need or evaluate a common instructional practice already in use. Further, teachers said they used student data to justify their search for alternative strategies to pilot with inquiry students. One teacher described this new emphasis:

Conversations during inquiry time are very data-driven. At other meetings, the conversations might be housekeeping, trips, behavior, etc. But the inquiry team discussions are more about data and what we will do next.

\section{Teachers value inquiry conversations because they take a more active role and show more initiative compared with other meetings. Collaborative inquiry created a forum for teachers to share their immediate classroom experiences and expertise, and to seek advice about their students who were struggling. More often than not, inquiry meetings were led by teachers. "The inquiry meeting is more like a discussion," explained one teacher, "not just one person talking and directing.” Teachers felt collaborative inquiry supported a}

conversation that valued teacher perspectives on student learning needs and potential responses. They noticed that teacher voices were shaping the focus and pace of inquiry meetings. "In the inquiry team, there are just more teachers talking," one teacher said. Many teachers shared that they felt freer to talk during inquiry time and saw more opportunities in the process to express opinions and ideas about their classroom practice and work with targeted inquiry students. This generated a positive pressure on all teachers to participate and speak up_- “even the reluctant ones,” noted an instructional coach. One teacher explained the value of this new emphasis on collaborative conversation.

During grade planning, administrators are telling us what unit we are to be working on over the next few months and what goals we need to meet for coverage. It is mostly them talking. ... In inquiry meetings, everyone has something to say and we all bounce ideas off each other. ... There are a lot of teachers talking. Our 45 minutes goes by fast.

\section{Teachers value inquiry conversations because they bring opportunities to establish new formal working relationships with other educators whose students share a common learning need.} Through participation on the core inquiry team, elementary school teachers valued the opportunity to examine shared problems of teaching and learning in their classrooms from a cross-grade perspective. New opportunities also came in small school settings when teachers in adjacent grades worked together as one inquiry team, e.g., teachers from grade 2 and 3 focused on student problems with decoding across their classrooms. For teachers, these opportunities for cross-grade conversations led to 
reflections on the consistency of teachers' instructional responses. It also presented teachers with opportunities to take a developmental perspective on the curriculum as students progressed from one grade to the next. Teachers appreciated inquiry because it enabled them to learn about common practices across grades and to think strategically with other teachers about aligning their instructional practice.

At the secondary level, inquiry teams were sometimes organized around populations of student who were struggling, such as $9^{\text {th }}$ grade newcomers, English Language Learners (ELL), or special education students, which cut across subject areas, grades, and/or role groups. The forming of inquiry teams provided a much-needed opportunity to bring together teachers from different departments with counselors and special education teachers. Teachers felt these new relationships were critically important, particularly when the learning needs associated with a student subpopulation had not been closely examined in the school. Through inquiry meetings, teachers were able to pool information to jointly diagnose a particular learning target and brainstorm about instructional strategies to test. Teachers credited these meetings with increasing coordination across classrooms and the consistency of teacher responses to specific student learning needs. It was also valued for streamlining the student support process in the school, integrating counselors into conversations about instruction, raising teacher awareness of available resources in the school, and identifying other areas needing coordination at the administrative level. Through the new inquiry teams, information about students who were struggling and responsibility for their learning became both shared and distributed across the school. As one secondary school teacher explained,

What collaborative inquiry has done is given us a way to work with more teachers and other departments. Before, we talked to teachers here and there but mainly we work with those who are in our immediate department. Inquiry has given us an opportunity to go outside of our departments and make those links real.

Summary. Across study schools, collaborative inquiry offered schools a new type of professional conversation. Teachers noticed and valued this difference because it enhanced the quality of their professional work and relationships. Inquiry conversations were reported to be more structured and focused on resolving the specific learning needs of students in their classrooms compared with other school meetings they regularly attended. Inquiry emphasized the use of student data from multiple sources to diagnose student learning and develop instructional responses. In some schools, inquiry presented an opportunity to establish new working relationships organized around specific student learning targets that would benefit from a pooling of information across grades, subjects, and roles. 


\section{Principal Leadership Style}

\begin{tabular}{|l||}
\hline Principal leadership that \\
supports shared decision-making \\
enhances teacher participation \\
and ownership of collaborative \\
inquiry. \\
\hline
\end{tabular}

Principal leadership is critical to school improvement. An important influence on the nature and quality of teacher engagement in collaborative inquiry was the leadership style of the principal. Across study schools, principals varied in their approach to configuring inquiry and in using insights from teacher inquiry to inform school-level decision-making. Principals' approaches to leading school-wide inquiry reflected three classic leadership styles-participatory, delegative, and authoritative.

Principals explained their approach to leading collaborative inquiry as reflective of their goals for developing the school and the role they envisioned for teachers in that process. Principals employing a participatory leadership style sought to strengthen shared decision-making between teachers and administration and empower teachers further to take initiative to improve the quality of teaching across the school. Principals employing a delegative leadership style used the introduction of collaborative inquiry to strengthen a fragmented or weak professional culture in their building and to stimulate responsibility across faculty for student learning. These school leaders largely left teachers on their own to implement inquiry. Principals employing an authoritative leadership style used the inquiry work to control and direct teacher learning by taking a strong supervisory role over teacher participation. These styles reflect different levels of trust between administration and teachers. They also reflect fundamental differences in the level of teacher involvement in decisionmaking within teacher inquiry teams and through a core inquiry team.

\section{In schools where principals take a participatory approach to leading} collaborative inquiry, teachers report strong benefits. Principals in five study schools employed a participatory leadership style that emphasized shared decisionmaking. Under participatory leadership, teachers and administration developed positive working relationships and were engaged in an ongoing dialogue about classroom practice and student progress. These schools tended to have a positive professional culture in place before the introduction of collaborative inquiry and a recent history of improving student performance.

Teachers characterized principals with a participatory style towards the inquiry work as "inclusive," "hands-on," "collaborative," and "empowering." These principals encouraged an "open dialogue" across the school focused on improving teaching and learning. This openness included providing teachers with opportunities to hear about the work of other inquiry teams and participate in ongoing conversations about the effectiveness of particular assessments and instructional practices in the school.

These principals viewed teacher engagement in collaborative inquiry as an engine for helping the school address the needs of its students who were struggling. Principals framed the progress and insights of individual teacher inquiry teams as important work for the school as a whole. 
They also empowered the core inquiry team as an active decision-making body responsible for facilitating the inquiry process, reviewing new inquiry findings, and identifying areas of the school program in need of strengthening. Under a participatory model, principals tended to establish new leadership roles for teachers as inquiry team facilitators. They also included teacher team leaders as formal members of the core inquiry team. Under participatory leadership, administrators and teachers were engaged in regular monthly discussions about how the inquiry work could identify needed school-wide improvements.

Principals leading with a participatory style tended to take part in the inquiry process at times. In some cases, principals would stop by inquiry meetings to check in with teachers to signal the importance of their work. They would receive brief updates from teacher teams directly, express interest in their next steps, and generally reinforce the importance of their work. In some cases, principals would sit in on teacher inquiry meetings, actively listening to teacher dialogue, asking occasional questions to further the discussion, expressing interest, and offering to expedite teachers work as needs arose. Here, one teacher characterizes the leadership style of her principal in relation to the inquiry work:

The principal is a listener to what we all discuss and then she takes that and processes it and helps us figure out the direction to take. She is looking at the school as a whole to see if there is something we need to do for the school. She brings that to the school leadership team too. It's not a dictatorship, but collaborative, although she is firm.

Under a participatory leadership style, principals framed the role of assistant principals as neutral facilitators of teacher inquiry teams with the goal of helping teachers maintain their ownership of the inquiry work. In this role, assistant principals described their contributions as posing questions to stimulate thinking, finding resources and information to advance teachers' work, taking notes for the team, and, in some cases, making comments that helped the conversation move with efficiency and include all voices.

In one school where the principal had adopted a participatory leadership style in her approach to inquiry, most teachers expressed strong views that inquiry had benefited the school and themselves personally. Teacher teams were able to complete 2-3 cycles of inquiry. They reported identifying effective assessment and instructional practices for their grade level. Individual teachers felt they had grown professionally, in terms of their instruction, use of data, leadership skills, and, at times, general knowledge of the school. These teachers expressed a strong sense of responsibility for student learning, which they attributed, in part, to the ownership they felt over the inquiry process itself. For teachers, the inquiry process presented an immediate opportunity for teachers to improve their practice and strengthen the larger systems of the school.

Under participatory leadership, teachers and administrators identified the current inquiry work as an important venue for leadership practice in their school. Teacher characterizations of "the leadership" behind collaborative inquiry suggested authority and influence within inquiry was dispersed among different role groups and spread broadly across the building. Both administrators and teachers tended to use collective terms to characterize the location of "leadership" within the school. In this 
context, teachers characterized leadership as "fluid” and encompassing "everyone," suggesting that through inquiry many individuals were simultaneously engaged in leadership practice, creating a leaderful school. One teacher's description reflects this view, which was prominent in schools under participatory leadership:

I think we teachers kind of take turns being a leader in our inquiry work. It is fluid. Sometimes it is the teacher with more years of experience. And there are days that I lead them with a fresh perspective. That is the true definition of leadership. It is this fluid thing depending on our expertise and comfort levels.

\section{In schools where principals take a delegative approach to leading inquiry, teachers report improvements in professional relations and in teacher responsibility for student learning.} Principals employing a delegative leadership style used the introduction of inquiry process to improve the professional culture of the school by encouraging teacher collaboration. In these six study schools, the teacher community had been fragmented and under strong external pressure to improve the school's accountability standing. Both administrators and teachers valued the inquiry process as an opportunity for faculty to learn to work together as colleagues, to share their knowledge, and to identify effective practices to support students who were struggling. It was an opportunity to open up and deprivatize classroom practice so that the conditions of teaching and learning across the school might be examined.

Principals employing a delegative style of leadership took a strategic hands-off role in inquiry, empowering teachers to forge new professional relationships. In elementary schools that situated inquiry within existing work groups, principals shifted facilitation responsibilities to teachers and away from assistant principals. As one principal explained, "We, administrators, try to stay away from teacher inquiry meetings so teachers can have an honest conversation about what is working or not.” In this scenario, teachers would invite coaches or assistant principals to participate as resources to their conversation at different points in the process.

In secondary schools, principals with a delegative leadership style asked teachers to form their own inquiry teams, which served to help teachers find colleagues struggling with similar problems of teaching and learning in their building. The goal was to empower teachers to take responsibility for the learning needs of low-performing students in their classrooms and to create an environment in which teachers could have open discussions about their practice. It was hoped that inquiry would enable teachers to better understand student learning needs"to get to know our students better," according to one principal-and assess the relative effectiveness of current classroom teaching, school programs, and any related policies. Explained one principal:

Teachers now have the opportunity and responsibility to take matters into their own hands with their inquiry teams. But we are taking it slow and that can be to our advantage. My role and the assistant principals' role is to support and to listen, but not interfere. It has to be nonthreatening. It has to be everyone's opinion heard. I can push teachers, but I do not want to pull them.

The role of administration was then to provide teachers with on-demand support in 
the form of materials or advice, typically through literacy or mathematics coaches or the support of Data Specialists in the building. In one large school, the principal formed a dedicated data team to help the numerous teacher teams quickly access background and performance information about their inquiry students. Principals maintained a general awareness of teacher inquiry work, keeping "in touch" with the process components of inquiry such as the regularity of teacher meetings, group dynamics, and general topics discussed. Updates on ARIS Inquiry Spaces made by teams or from reports from coaches were primary sources of information.

Principals with a delegative leadership style used the core inquiry team as a source of support for teacher teams rather than as a school-level decision-making body. In this role, members on the core team who were experienced with inquiry served as a resource to clarify the inquiry process and troubleshoot resource problems for teacher teams. On an intermittent basis, the principal used the core team to convene teacher inquiry facilitators in a roundtable-style discussion of the progress of each team. The goal was to raise general awareness of the work of all inquiry teams. In a few instances where teacher teams generated ideas that would require a change in policy or new coordination, a team representative simply contacted the principal directly.

A delegative leadership style was a useful strategy for jump-starting inquiry in specific school contexts, but it had its limits. In a number of schools, both the principal and teachers expressed interest in more coordination across teacher teams and a decision-making process for reviewing inquiry findings and recommendations to benefit the school as a whole. Towards the end of the school year, principals expressed being pleased with the new level of ownership that teachers were taking for student learning through the inquiry work and with the collective effort underway across the school. At the same time, principals were also well aware of an "uneven" quality of inquiry work across teacher teams in the school. They also noted duplication in efforts by some teams, although this often resolved itself as teachers initiated joint meetings to share insights and combine efforts. At the same time, as teacher relationships grew stronger and a culture of conversation about practice began to take root under a delegative leadership style, teachers became interested in the larger purpose - the "big picture"- of the inquiry work permeating the school.

Teachers at these schools still found value in the inquiry process for themselves, their inquiry students, and other teachers, but saw the potential for even more benefits at the school level.

The dramatic shift in responsibility to the teacher teams created a desire among teachers for more structured engagement between administration and teachers and for conversations about how inquiry might inform school-level decision-making. This desired shift in relationships and influence suggests that once teacher inquiry takes root, principals may need to adopt a more participatory style of leadership. This would include providing more guidance and setting expectations for inquiry teams, while sustaining their ownership and initiative. It would include formally integrating the inquiry work into decision-making bodies in the school so that new insights from inquiry would help improve key systems, namely the policies and practices defining school curricula, assessment, instruction, and resource allocation. 


\section{In schools where principals take an authoritative approach to leading inquiry, teachers feel little ownership of the inquiry work and limited benefits to themselves and the school. Principals in only two study schools employed an authoritative leadership style in overseeing teacher participation in collaborative inquiry. Teacher inquiry work was typically led by administration with teachers placed in a responding role. Teachers saw little room for initiative or ownership of the inquiry process. Administration was hesitant to allow teachers to work independently as a team, which inhibited teacher willingness to openly discuss specific problems of teaching and learning in their classroom. Because administration did not value inquiry as team work, teacher meeting time was often not protected. The core inquiry team was dominated by the input and presence of administration, with teachers in a listening role and simply expected to "report back" conversation topics and new directions. In this context, teachers were generally frustrated by low levels of trust between faculty and administration around the role of teachers in school improvement. Teachers tended to be positive about the potential for collaborative inquiry, but felt the supervisory role taken by the principal and administration was inhibiting. Few teacher teams felt their inquiry process had produced insights worth sharing beyond their team.}

Summary. As this analysis shows, the principal's leadership style was an important influence on the nature and quality of teacher engagement in inquiry. From a theoretical point of view, it is not surprising that collaborative inquiry was most positive and productive in schools where principals had adopted a participatory style of leadership. Inherent in the concept of collaborative inquiry is the idea of shared decision-making, particularly when inquiry is harnessed as a process for school improvement. In contrast, it is not surprising that collaborative inquiry was the least positive and productive in schools in which principals adopted an authoritative style of leadership, which reinforced the hierarchical power relationship between administration and teachers. An authoritative style of leadership contradicts the core purpose of collaborative inquiry because it inhibits the ability of administrators and teachers to work together in partnership, which is a foundation for joint decision-making and for developing shared knowledge about classroom practice.

The use of a delegative leadership style by most principals served to build teacher capacity for collaboration and to cultivate a collective commitment among groups of faculty to meet the needs of students who have not been successful. Little attention had focused on establishing a core inquiry team with decision-making authority to consider how individual team findings might guide adjustments to school programs or resources. As was noted in the analysis, in a number of schools where inquiry teams were somewhat disconnected from administration, both teachers and administrators expressed interest in stronger coordination. They also expressed interest in creating a venue for teachers and administrators to share team findings and consider their implications for the school. In these contexts, a participatory style of leadership may help administration advance the inquiry process from its current state as a collection of independent teams into a broader improvement process where new knowledge is shared broadly across faculty and informs school-level changes. 


\section{Supporting Teacher Leadership}

\section{Inquiry Work Creates Powerful Opportunities for Teacher Leadership.}

Traditionally, school leadership has been associated with a few formal positions in the school. This view greatly restricts the possibilities of leadership practice. Most importantly, it overlooks the important contributions teachers can and must make to ensure that schools are effective and that improvements in teaching endure (Harris \& Muijs, 2004; York-Barr \& Duke, 2004).

Collaborative inquiry offers teachers unique opportunities to work and take joint action on matters of importance to the school. As described earlier, the inquiry process situates within teacher inquiry teams the responsibility for developing innovations to improve student learning. The development of leadership practice can grow as teachers see new opportunities for real and important roles in the development of their school. Leadership practice by teachers is more often associated with opportunities for collective action. It is cultivated by providing teachers occasions to share expertise and contribute to common tasks (McLaughlin \& Talbot, 2006).

In our interviews, teachers associated new or expanded opportunities for leadership practice with their engagement in collaborative inquiry. Leadership practice is embedded in the collaborative process itself_-teachers taking collective action to understand a particular problem of student learning, develop effective instructional responses, and use new knowledge to improve their practice and contribute to the development of the school. This shift in responsibility to teachers, characterized as “empowerment” by many, was motivating for teachers. They reported more control over their teaching because inquiry helped them address, in concert with others, persistent problems of student learning in their classrooms. One teacher explained:

Inquiry is an opportunity for teacher leadership because it gives you control over your own teaching. It gives you ownership and more autonomy in the classroom. It makes you want to do more and make your colleagues do more because you see the benefits of it all and you see how it impacts the students in a positive way.

When talking about opportunities for teacher leadership through the collaborative inquiry process, teachers also spoke of the fundamental commitments that motivated their participation - to see their students be successful, to continue to grow as professionals, and to improve the knowledge and practice of other teachers with similar responsibilities. These commitments provide a strong basis for leadership practice. As one teacher noted, "Leadership is about being committed to being a better teacher. Inquiry provides an opportunity. Engaging in inquiry is a demonstration of that commitment."

Teachers identified a number of opportunities for developing leadership practice through inquiry. These opportunities stretched from an individual teacher working with students in her classroom, to teachers engaging in dialogue and joint work as inquiry team members, 
and finally, to teachers contributing to the broader development of the school. These involved:

- Teacher leadership in the classroom;

- Teacher leadership to develop collective knowledge of current classroom practice;

- Teacher leadership to develop collective knowledge of effective classroom practice;

- Teacher leadership to facilitate the learning process of the inquiry team; and

- Teacher leadership to advance school improvement.

The leadership opportunities identified by teachers reflect an expanding scope of influence in the school and a source of motivation to teachers to improve their practice. They also represent a concrete expression of teachers taking responsibility for student learning through their participation in a collaborative inquiry process. Higher levels of engagement with collaborative inquiry brought teachers greater opportunities to develop their leadership practice. There also was an association between levels of teacher engagement and different styles of principal leadership.

\section{Teacher leadership in the classroom.}

Across all study schools, teachers felt a basic form of leadership practice was rooted in individual action to improve their classroom practice for those students in their charge (Warren Little \& McLaughlin, 1993; York-Barr \& Duke, 2004). "Kids look up to you for leadership in the classroom," noted one teacher. In the context of collaborative inquiry, such heightened personal commitment taps a new source of energy and expertise as teachers work with inquiry students and engage in conversation with peers. Teachers reported that their work with inquiry students had the effect of revealing other aspects of their practice that needed attention. Through team conversations, teachers reported picking up new ideas and practices beyond the immediate focus of their team inquiry. Brainstorming with colleagues uncovered new strategies and ways of thinking. It also helped teachers take notice of the strengths of other teachers in the building whom they could approach for advice. Classroom-based leadership through inquiry was a common response when teachers were asked about leadership opportunities through collaborative inquiry. For study schools in which collaborative inquiry was well supported, teacher leadership for student learning provided a foundation for other forms of leadership practice that focused on developing shared knowledge about teaching practice. Said one teacher:

All of this really helps us to be leaders of our own class. We are able to take charge of our classroom and be the leader. And as a teacher, inquiry helps us to reflect on things that we have to do. You cannot be a leader of teachers if you do not know what to do in your own classroom. Each teacher has an opportunity to get better at teaching.

\section{Teacher leadership to develop collective} knowledge of current classroom practice. Other opportunities for developing teacher leadership come through inquiry team conversations in which teachers step forward to share their opinions, knowledge, and experience in responding to particular student learning needs. This also includes 
teacher contributions to collective brainstorming about alternative interpretations of student assessment data and the range of instructional responses currently used in the school. Teachers in some teams were able to conduct lowinference observations of each other, taking note of the lesson content, strategies used, and student response. Developing shared understandings of the current state of teaching and learning in a schoolsometimes characterized as "knowledge of practice"-is a form of leadership essential to teacher capacity for joint action (CochranSmith \& Lytle, 1999). In this context, teacher contributions to team learning reflect a strategic effort to bring to the surface and share information about current classroom practice. This sharing enabled teachers to develop a common understanding of the state of teaching and learning across classrooms and a better understanding of specific problems of practice.

In many settings, inquiry triggered a revolutionary conversation in the school because teachers had little previous knowledge of what took place in other classrooms. Particularly in schools where the principal used the inquiry process to strengthen professional dialogue, leadership practice was associated with teacher initiative to contribute to open discussions about their instruction and use of assessment. Participation meant taking risks for a number of teachers because the inquiry work represented an initial step in deprivatizing classroom practice across the school. Teachers credited inquiry with encouraging "reserved" teachers to "open up" and participate. This growth in participation and openness suggests that the conditions of teaching and learning in the school were becoming more widely known, at least at an inquiry team level. Reflecting with other teachers about their collective instructional choices was a form of leadership practice because teachers were taking responsibility for student learning beyond their immediate classroom. Two teachers offered their perspectives:

I see leadership opportunities because we are coming together. People who might have been a little bit more reserved to share information, they have definitely opened up. They are saying to us, "Hey, you have the same problem I do, so let's take a look at this together." People who might have a little bit more of a reserved personality, because of inquiry they are thinking to themselves, "I need to speak up and assert my opinions.”

We all have a stake in the inquiry team. We all communicate with each other. After we find out what is going on in everybody's classrooms, then we decide together, as a team, what are the steps that we can make in order to move forward with this child. In my department, I can truly say that we work as a team and we all play our parts.

\section{Teacher leadership to develop collective knowledge of effective classroom practice.} For teachers, leadership practice was also associated with a collective effort to identify effective teaching strategies. This form of leadership practice emerged through team conversations as teachers developed a shared understanding of how and why some instructional choices were more effective than others, often characterized as "knowledge for practice" (Cochran-Smith \& Lytle, 1999). Teachers contributed when they conducted research on behalf of their inquiry team or brought student work to evaluate a current practice in use. Through conversation, teachers developed a shared understanding of the relative merits of 
different strategies. Collaborative inquiry supported leadership practice as teachers contributed to the collective understanding of best practice within their team. Two teachers offered insight into some aspects of this process:

We are bringing all these ideas to the forefront and everyone's trying it. Someone could definitely have the opportunity to become a leader. Absolutely, inquiry lends itself 100\%. I feel this because it is not just up to one person. We are not listening to one person giving us the ideas. We are bouncing them off each other, back and forth. And we're choosing the strong points we would like to highlight.

I think teachers are taking more of an active leadership role through inquiry. They are speaking up about problems that they see with their students and asking others about how to solve some of these problems. Other teachers then can step up and suggest solutions. So those teachers are taking leadership roles too.

\section{Teacher leadership to facilitate the} learning process of the inquiry team. When asked about opportunities for leadership, teachers also spoke of their efforts to sustain the collaborative nature of their teamwork (Gronn, 2003). For teachers, leadership practice focused on supporting broader participation by all members in discussions of teaching and learning. It also focused on creating processes that facilitated the distribution of knowledge among members or the matching of teacher expertise/skills with the tasks of inquiry. Since the process of collaborative inquiry encourages teacher leadership, it is not surprising that teachers worked in concert to support the collaborative process itself.
In the inquiry team context, teacher leadership practice focuses on the development of shared knowledge among teachers through common experiences and responsibilities. A number of teacher teams decided to rotate the position of team leader among members. This enabled each participating teacher to develop facilitation skills. It also enabled members to rotate attendance to the core inquiry meeting so that all teachers represented their inquiry work to others and contributed to conversations with administration. Leadership practice also focused on tapping teacher expertise to suit the inquiry task at hand. "Each person gets to be a leader in a different area," was a common response. In some situations, this was about leveraging the array of emerging skills across the team as teachers constructed a shared understanding about teaching and learning across their classrooms. It reflected an effort by teachers to pool expertise within the inquiry team to support different tasks of inquiry, with teachers stepping forward as their expertise becomes needed. A teacher described how team dynamics reflected this form of teacher leadership:

I think inquiry has allowed different teachers to find their own expertise. Some people are really good at identifying problems. Some teachers have been here for a long time, so they are really good at seeing how things fit together and what might work in the end because they've seen so many different things happening. There are newer teachers who are open to new ideas and will bring new ideas to the team. The facilitator is in charge of synthesizing all of our ideas so we are all heard. ... We really stress collaboration in our team, so in the end inquiry is helping us do that. 
Other approaches to tapping teacher expertise followed each cycle of collaborative inquiry. When inquiry teams identified a new student learning need to address, a team member with some expertise stepped forward to facilitate the work. Some tasks were administrative in nature but were still important to ensuring that teachers had the tools and information needed to diagnose a specific learning need and implement an appropriate instructional response. This form of leadership practice was visible in the coordinated facilitation of the team as a whole. It reflected a commitment by teachers to sustain the collective contributions of all members in all aspects of the inquiry teamwork. A teacher described this form of leadership:

Yes, absolutely there are opportunities for teacher leadership because when we start a new inquiry cycle different teachers take over the team roles. We are all strong in some way. When we meet, each teacher will guide the group depending on what we are discussing from the classroom. They find the research, ask for prior conditions of learning, etc. We each have our own role, but it is in a collaborative effort. The teachers provide each other with a lot of guidance and leadership.

\section{Teacher leadership to advance school improvement. Through collaborative} inquiry, teachers found new opportunities to contribute to school improvement. To this end, collaborative inquiry supported teacher leadership practice in two important ways. The inquiry work enables teachers to gain a leadership perspective on their school by raising their awareness of the overall direction of the school and opportunities to contribute to its development. This awareness and commitment provided a basis for leadership practice as teachers learned to think strategically about how their instructional choices and coordination with peers were influencing the performance of the school. One teacher explained:

A lot of times, teachers do not understand why certain decisions are made. Well, being a part of inquiry allows teachers to understand that decision-making process because they are also a part of that process. They have a sense of where the school is going. And this is vital to taking more ownership in the school and becoming more of a leader. I see teachers becoming more invested in what the school was trying to accomplish. Inquiry provides one way for teachers to take more of a leadership role by taking more of a leadership perspective.

Teachers found other opportunities to exert leadership through participation in a schoollevel decision-making process that focused on developing the school. This opportunity came through the establishment of inquiry team leaders in some schools who presented their team findings along with other information to administration, coaches, and faculty for broader discussion. In some schools, inquiry provided teachers access to a formal venue for informing their principal's decisions. Teachers also developed an understanding of the direction of the school and progress to date- that is, developing a "leadership perspective" on how individual and group actions contribute to school improvement.

Teachers greatly valued this new point of view. As described earlier, some inquiry teams chose to rotate the role of team leader so that each teacher had an opportunity to attend core inquiry team meetings as a way to expand their awareness of the school's development. Said one teacher: "I think 
within grade-level teams, leadership is developing because we take turns. ... All our team roles are rotated to build capacity and collaboration."

Teacher opportunities for leadership practice align with school engagement in collaborative inquiry and the leadership style of the principal. Table 1 presents a progression of leadership opportunities for teachers at the class, inquiry team, and school level by principal leadership style. Higher levels of teacher engagement, present in schools in well-developed or advanced stages of inquiry, provided teachers opportunities to develop their leadership practice at the class, inquiry team, and school level. These schools were led by principals with a participatory style of leadership who positioned inquiry as a school development process and who shared decision-making with teachers through the school's core inquiry team. Moderate and lower levels of teacher engagement, present in schools in emergent and beginning stages of inquiry, provided teachers opportunities to develop their leadership practice at the class and inquiry team level. These schools were led by principals with a delegative style of leadership who used inquiry to strengthen teachers' professional relationships and collective responsibility for student learning. These principals emphasized building strong teacher teams and did not establish formal mechanisms for disseminating inquiry team learning or for integrating new insights into school-level decision-making. Teachers reported some expanded opportunities for teacher leadership that extended from the classroom to their teacher team, but not as much at the school level. Finally, low levels of teacher engagement, were reported in schools in the beginning stages of inquiry in which the principal used an authoritative style of leadership to establish inquiry. Most teachers reported no authentic opportunities for teacher leadership beyond their own initiative to support inquiry students in their classrooms.

Summary. Teachers identified a number of opportunities for developing leadership practice through inquiry. These opportunities extended from an individual teacher working to meet the immediate needs of struggling students in her classroom, to teachers engaging in dialogue and joint work as inquiry team members and, finally, to teachers contributing to the development of the school. A participatory style of leadership maximized teacher opportunities for leadership practice.

Table 1.

Progression of Teacher Leadership Opportunities in Collaborative Inquiry by Principal Leadership Style

\begin{tabular}{lllll}
\hline \multirow{2}{*}{$\begin{array}{c}\text { Leadership } \\
\text { Style }\end{array}$} & \multicolumn{3}{c}{ Opportunities for Teacher Leadership } & $\begin{array}{l}\text { Number } \\
\text { of Study } \\
\text { Schools }\end{array}$ \\
\cline { 2 - 4 } & $\begin{array}{l}\text { Student/Class } \\
\text { Level }\end{array}$ & $\begin{array}{l}\text { Teacher Inquiry } \\
\text { Team Level }\end{array}$ & $\begin{array}{l}\text { School } \\
\text { Level }\end{array}$ & \\
\hline Participatory & Yes & Yes & Some & 5 \\
Delegative & Yes & Some & Limited & 6 \\
Authoritative & Yes & Limited & None & 2 \\
\hline
\end{tabular}




\section{Extending the Leadership Pipeline to the School}

\section{The inquiry process helps create a pipeline of leadership from within the school.}

Forward thinking school districts develop an in-house leadership pipeline that runs from the classroom to the central office to cultivate future leaders. Creating a pipeline that reaches every level of the system can reduce the uncertainty and transition time that comes with turnover in administration and coaches. Through stronger connections with local schools, districts can attract and groom teachers with a track record of successful classroom practice and substantive contributions to their professional community. Tapping effective educators within the system brings into the ranks of administration first-hand knowledge of the challenges of teaching and learning in their local district. These new leaders also bring valuable experience using the assessment and instructional resources available to local schools to advance student learning.

\section{The collaborative inquiry process can} help school leaders create a leadership pipeline within the school. There is strong alignment between the collaborative inquiry process and the School Leadership Competencies (2008) adopted by the Department to guide the development of aspiring and current school leaders across the region. School leadership is conceptualized along five core competencies:
- Personal Leadership: Fosters a culture of excellence through personal leadership.

- Data: Uses data to set high learning goals and increase achievement.

- Curriculum and Instruction: Leverages deep knowledge of curriculum, instruction, and assessment to improve student learning.

- Staff and Community: Develops staff, appropriately shares leadership, and builds strong school communities.

- Resources and Operations: Manages resources and operations to improve student learning.

Each core competency is composed of three to seven elements that detail the goals, dispositions, practices, and outcomes of school leadership. For each competency and element, the development of school leaders advances through six stages: from none to emerging, developing, and proficient leadership competency, and finally to mastery and exemplary leadership. The school leadership competencies and elements are presented in Figure 3.

Participation in collaborative inquiry is likely to help both potential and current school leaders develop a range of leadership competencies. For emergent and developing leaders who are current administrators and instructional coaches in formal school leader positions, collaborative inquiry may offer opportunities for continued development in at least four core competencies. Specifically, it may offer school leaders the following opportunities:

- Developing personal leadership to influence others to achieve results; 
- Analyzing data from multiple sources and identifying student learning trends to set goals and monitor and modify instruction;

- Strengthening curriculum and instruction by supporting teachers in the use of effective instructional strategies;

- Developing effective teachers and building strong teacher teams with leadership capacity; and

- Developing strong school community by establishing systems that promote learning, collaboration, and communication across the school.

Through inquiry, current school leaders may also find opportunities to sharpen their skills in the management of school resources and of school-level programs that support student learning. Specifically, as teacher inquiry teams identify effective strategies, administration will need to determine how best to integrate new learning and materials into the school's curricular program or to reallocate related resources, such as time for instruction or planning and new professional development needs.

For potential leaders-namely, teachers who are expressing initial interest in a leadership position-inquiry offers opportunities for development in at least three core competencies. These include

- Developing personal leadership by cultivating beliefs and practices that reflect a commitment to improving student achievement and influencing others;
- Developing staff by building strong teacher teams with leadership capacity; and

- Strengthening curriculum and instruction by developing and using effective instructional strategies and assessment routines to meet students' diverse learning needs.

Across study schools, a number of administrators and teachers reported new opportunities for their own leadership development through the collaborative inquiry process. First, current administrators and coaches in formal school leadership positions saw opportunities to hone their leadership skills through inquiry. Second, collaborative inquiry spurred the emergence of potential leaders among teachers who were beginning to consider school administration as a career focus. This included teachers who were actively pursuing administrative certification and those beginning to contemplate administration as a career path.

\section{Development opportunities for current school leaders through collaborative} inquiry. Across most study schools, principals tapped assistant principals or instructional coaches to help launch collaborative inquiry and establish a schoolwide system for supporting teacher collaboration. The assistant principals and instructional coaches also examined schoolwide performance data to note learning trends. And they led their administration through key decision points in the configuration of inquiry and in designing a goal-setting activity to launch inquiry. They also introduced the process to faculty, assisted the principal in setting expectations for the inquiry work, and in some cases recruited effective teachers to become inquiry team facilitators/leaders. Teachers 
Figure 3.

\section{New York City School Leadership Competencies}

\section{Personal Leadership: Fosters a culture of excellence through personal leadership}

- Believes all students can achieve at high levels. Articulates a clear vision and goals for high student achievement.

- Holds self and others accountable for student learning.

- Strategically aligns leadership behaviors with stated values and goals to drive required change. Develops strategic plans with effective solutions. Adapts appropriately to situation, audience, and needs.

- Influences others to achieve results. Builds strong relationships based on mutual respect, trust, and empathy.

- Communicates clearly and appropriately for the audience and message.

- Demonstrates self-awareness and a commitment to ongoing learning. Welcomes and acts on performance feedback.

- Demonstrates emotional fortitude and perseveres in the face of obstacles.

Data: Uses data to set high learning goals and increase student achievement

- Demonstrates ability to understand and analyze data from multiple sources.

- Uses data to identify student learning trends, set goals, monitor and modify instruction, and increase student achievement.

- Develops school culture and practices that rely on data to inform adult learning, professional development, and decision-making.

Curriculum and Instruction: Leverages deep knowledge of curriculum, instruction and assessment to improve student learning

- Develops, implements, and evaluates rigorous curricula to accelerate learning for all students.

- Supports teachers in using effective instructional strategies to meet students' diverse learning needs.

- Regularly assesses student learning and ensures the provision of specific, timely feedback to teachers and students.

- Aligns standards, curricula, instructional strategies, and assessment tools.

Staff and Community: Develops staff, appropriately shares leadership, and builds strong school communities

- Recruits and selects effective teachers.

- Improves classroom teaching by setting clear expectations and observing, coaching, and evaluating teachers and staff.

- Supports the development of all teachers. Stimulates and retains high performers, mentors early career teachers, challenges low performers to improve, and dismisses poor performers who do not improve.

- Builds strong teams, develops leadership capacity among staff, and shares responsibilities appropriately.

- Establishes systems that promote learning, collaboration, and communication throughout the school.

- Listens effectively to families, students, and the school community. Proactively engages the school community around the school's learning goals.

\section{Resources and Operations: Manages resources and operations to improve student}

learning

- Develops and implements systems and processes to ensure effective operations that support student learning.

- Manages time in relation to student learning priorities. Brings projects to completion.

- Allocates and manages budgets and resources effectively in support of learning goals.

- Aligns youth development and support services around academic goals. 
considered these school leaders to be the leadership behind inquiry along with the principal. And principals, in turn, credited the coach or assistant principal who helped launch the work with its successes to date.

School leaders also sought to provide ongoing support to individual teacher inquiry teams. In this role, assistant principals or coaches had the opportunity to build strong teacher teams in the school and help those teams develop leadership capacity. It also helped them establish positive relations with teachers and exert influence in a manner that reflected mutual respect. Effective school leaders took on this role by serving as neutral facilitators who emphasized teacher participation and responsibility in directing inquiry. One coach described her development in this role:

Yes, inquiry relates to my personal professional goals because I have learned how to delegate responsibilities. I have learned to use protocols for running meetings, and how to get everyone involved which helps build my administrative skills.

In some schools, school leaders met separately with teacher inquiry leaders as a group to coach them in the inquiry process itself, in the management of group dynamics, and in identifying resources that helped advance each team's inquiry, such as student performance or classroom observation data and instructional strategies. In this role, coaches and assistant principals were developing the capacity of their teachers to evaluate instructional choices and to work together collaboratively. A coach who had recently completed her administrative certification felt she had developed personal leadership skills and strengthened the professional culture of the school through the inquiry work:

Leading the inquiry process has helped me develop my people skills. We have big inquiry groups and all teachers do not want to participate or the teams are moving slowly. So I'm learning how to get the message across and to get them on board without making them feel put upon, without saying, "We have to do this." I am learning how to speak to people and to make them feel comfortable with me. It helps me develop my professional self. It forces me to provide evidence and a rhyme and reason to what we do. In the past, I may have downplayed that. In the past I emailed what to do, but did not tell teachers why. My role now is forcing me to step back and understand why I am doing it and to use the process to roll it out correctly.

Leading the inquiry work in the school also brought opportunities to develop their knowledge and application of available student performance data to improve the school. School leaders reported two areas of growth in this regard. First, school leaders felt their general knowledge of available data and its use in guiding instruction continued to grow through inquiry. The inquiry process helped school leaders think about how to integrate multiple sources of data to note trends in student performance and set goals for instruction. An assistant principal leading the inquiry work credited inquiry with expanding her knowledge and use of different assessment resourcesespecially their application in diagnosing learning targets and monitoring student progress. She explained:

Data analysis is tremendous in our inquiry teams and I am being educated 
about how to use all these resources effectively across the board. It has opened my eyes in terms of acknowledging the importance of formative assessments. Now we get areas that students are struggling with and are looking at particular questions. We can be very data-focused now and I have been growing in this way over the past couple of years. We think so much about the end-of-the-year goal, sometimes we neglect the student work, conferencing, going over rubrics, making sure the test matches the goal, and the needs and goals of your population. Facilitating the inquiry conversations and working with teachers is definitely helping with that.

A second area of growth for current school leaders was found in the opportunity to use data to think systemically about needed changes school-wide. The principal often relied upon a coach or assistant principal to prepare the agenda for the monthly core inquiry meeting. Effective preparation for some focused on reviewing the progress and findings of current inquiry teams to identify areas of omission or to strengthen the school's instructional program. It also included conducting preliminary analyses of new performance data to note trends and identify implications for the inquiry work underway. One assistant principal reported professional growth as she reviewed the school's current assessment portfolio and data collection routines in light of recent inquiry findings.

As an individual professional, the inquiry work has been a tool of reflection for me. We have a meeting for the core inquiry team and I am trying to come up with new ways to collect and look at data for the school. I am researching and trying to find new things that we have not already done. I am basically doing professional reading and collaborating with other schools. And I am talking with teachers.

\section{Development opportunities expand for teachers actively pursuing school administration as a career path. In every} school in this study, administrators were quick to identify teacher leaders who had recently earned or were pursuing certification to enter school administration. Principals typically encouraged the development of these teachers by inviting their attendance at the school instructional cabinet or school leadership committee. But with the introduction of inquiry, these emergent leaders found new opportunities to cultivate their leadership practice in the formal role of leader/facilitator of a teacher inquiry team, some appointed by the principal, others selected by their peers. As a team leader/facilitator, these teachers used the opportunity to gain experience leading conversations focused on strengthening school curriculum and to hone their facilitation skills to ensure their teacher team was productive and felt empowered. In schools where the core inquiry team was a decision-making body, these teacher leaders valued the opportunity to participate in conversations focused on strengthening the school as a whole. One teacher explained the connection:

I am an inquiry team leader. I think teachers like the way I work so they nominated me at the professional development session. I am very involved in curriculum. It is one of my passions. I started the administrator certification program and have been on the instructional cabinet. I want to be a school leader and inquiry was an opportunity to do that and develop some 
of those skills. And professionally, I always want to improve student learning.

A number of assistant principals already were actively supporting teachers as were coaches who were seeking administrative certification. The inquiry process provided yet another venue for administrators to identify teachers with leadership potential. The assistant principals believed the inquiry process was an opportunity for teachers to develop the dispositions and skills needed for school leadership through membership on the core inquiry team and teacher teams. One administrator's viewpoint was shared by many, namely that teachers leading the inquiry work, particularly as facilitators, were developing an analytical capacity to think systemically about both the learning needs of students and how to gain teacher support through dialogue. She explained:

In grade 4 several teachers went to get their license for the principalship and teachers begin to think, "I can do that." You can do my job. Teachers have talents. We need to develop them. I also see potential in the grade 2 facilitator; she is rising. In inquiry, as you dig and go deeper in the child you begin to learn about yourself. Can you have a sustained conversation about a child and what you want for them? Can you focus on all the different issues that surround one child, one group, one grade? Can you be as analytical as you need to be when trying to help other teachers? If you can, there is place for you in administration.

\section{Teachers with potential for school leadership surface through collaborative inquiry. Administrators often see their role as that of a talent scout tapping the next generation of school leaders. Administrators credited the inquiry work with bringing to their attention teachers they had not}

previously viewed with leadership potential. Before inquiry, some teachers were described by others as "quiet," "reserved," and "withdrawn" during teacher meetings, and less willing to engage in conversations about instruction around administrators. This changed during inquiry meetings. Administrators reported seeing these teachers "in a new light" because their interactions with peers and with administrators dramatically shifted with the launch of inquiry. Some previously "inactive" teachers agreed to take on team leader roles. Principals and others reported being "surprised" by their initiative and knowledge of student learning. During inquiry meetings, once "quiet" teachers actively contributed and were also attentive to facilitating other teachers' contributions. One teacher reflected on her own transformation:

I used to be really kind of quiet. I would just be in the background. Now, being a facilitator, I've learned how to speak up, but also to incorporate other people's opinions. It's been a really great learning experience for me. Now I speak whenever I have something that I think I can contribute.

These potential leaders were seen as sharing their classroom practice and asking questions of other teachers, taking initiative in preparing for inquiry meetings, and exerting influence on other teachers during inquiry conversations.

Also, some teachers themselves reported feeling increased energy and commitment as they worked with inquiry students and met with other teachers. These teachers reported personal surprise at their own behavior and the strong opinions they were developing about what could and should be done to support students who were struggling. One 
teacher who felt she had grown as a leader through the process said, "I had no idea I could be this involved. I have so many ideas." For teachers who had reluctantly taken on a team leader role, the experience helped them realize their potential as school leaders. Teachers reported stronger beliefs and practices about effective instruction and a commitment to improving student learning in concert with others. One teacher who reluctantly assumed a team leader position shared her growth in this new role:

I think that doing inquiry has really reshaped the way that I look at the school and the people that I work with here. ... The other teacher facilitators on the instructional cabinet have a real passion for the students and also for becoming better teachers. That has been really inspiring to me and has made me really want to incorporate new things into my own lesson plans.

These teachers with potential for school leadership were also beginning to think strategically about improvements beyond their immediate classroom. As described earlier, the opportunity to serve as an inquiry team leader had the effect of altering teachers' views of themselves as leaders. In these formal roles, teachers valued both their role in supporting other teachers and also the opportunity to "think bigger" at the grade or school level. One teacher, for example, valued her new facilitation skills because they helped her support fellow teachers and strengthen the inquiry team as a whole:

Inquiry has really taught me how to facilitate and listen to people more effectively. People spend time trying to voice their opinions in the best way they can and I have learned how to take things they have said and relay it back to the team in a more positive manner so that the other teachers could hear what the person was saying. I've learned how to be a better leader, to become more approachable. Some things have been brought to me about my leadership style and that's really made me rethink how I'm coming across to other teachers.

Both administrators and teachers viewed the new level of participation as a form of leadership practice. This change in some teachers' behavior took place in schools where classroom practice had long remained private and teachers had limited opportunities to discuss problems of student learning together. Principals attributed newly vocal teachers to their taking ownership over instructional improvement through the inquiry work. One principal explained:

More empowerment through inquiry is how we are developing people. Staff get to reveal their character in different times and situations and I began to see and hear voices I had not heard before through the inquiry work. It's because their skills and abilities are recognized as members of the inquiry team. It allows teachers to be heard, possibly for the first time or at different levels or in a different realm. Before, they were just one of the different departments, but now in a small team they are seen with the ability and the knowledge base and so are listened to.

Administrators were both surprised and excited by the positive changes in participation and commitment shown by some teachers in their inquiry work.

Summary. Collaborative inquiry can be a resource for cultivating leadership at the school level. There is strong alignment between the competencies the Department 
seeks to cultivate in school leaders and the goals and activities of collaborative inquiry. As a formal leader or participant in the inquiry work, administrators, coaches, and teachers can further develop the dispositions, skills, and knowledge needed for effective school leadership. These may include developing personal leadership; the use of data to set high learning goals and increase achievement; the ability to leverage their knowledge of curriculum, instruction, and assessment to improve student learning; and the ability to develop staff, share leadership, and build strong school communities.

Across study schools, administrators, instructional coaches, and teachers felt their participation in collaborative inquiry helped to cultivate the competencies they needed for school leadership. Current school administrators involved in leading inquiry in their buildings and facilitating teacher meetings felt it enhanced their leadership skills. The collaborative process also served to cultivate potential school leaders among teachers. For those actively pursuing an administrative certificate, they found opportunities to develop personal leadership, build teacher teams with leadership capacity, and develop effective instructional strategies to meet students' diverse learning needs. Participation in collaborative inquiry also brought to the surface potential school leaders. The leadership opportunities and distinctiveness of inquiry in the school helped some teachers begin to consider their potential for school administration. In these ways, the collaborative inquiry process can strengthen the leadership pipeline at the school level. 


\section{Establishing Inquiry Teams}

\section{Leveraging existing teacher groups facilitates inquiry work more easily than implementing new team structures.}

To support collaborative inquiry schoolwide, school leaders must consider how best to configure the inquiry process in their school. There are two important decision points in this regard:

- Identifying groups of teachers who can engage in collaborative work as inquiry teams, and

- Identifying a school-level decisionmaking body to think strategically about how best to leverage the outcomes of teacher inquiry for the development of the school.

The experience of study schools suggests that inquiry work is more easily supported when school leaders leverage previously established collaborative teams and meeting times.

Across most study schools, principals have leveraged existing teacher teams and meetings as a strategy for school-wide engagement in inquiry. This approach facilitates both the inquiry process itself and the logistics of team meetings. Specifically, school leaders frequently embedded the inquiry process in existing teacher gradelevel groups (e.g., $3^{\text {rd }}$ grade), subject-area departments (e.g., English or mathematics), and special student population work groups (e.g., ELL or special education). Existing teacher work groups typically reflected a common focus and responsibility for a specific area of the curricula, such as $2^{\text {nd }}$ grade literacy or $9^{\text {th }}$ grade biology. This shared responsibility provided an important basis for inquiry teams to identify common learning needs across classrooms for investigation. It also facilitated collaboration because teacher conversations reflected a shared knowledge base of current instructional strategies and assessments used with specific curricula, which supported reflection on the conditions of teaching and learning across classrooms. Teachers with common responsibilities also reported feeling invested in the productivity of the inquiry team because their insights enhanced both student learning and teacher professional knowledge. Finally, using existing group structures minimized logistical conflicts for teachers because the team schedule was already built into the school calendar and meeting routines were well established.

In schools that did not leverage existing work groups, the implementation of inquiry was more difficult because participation was inconsistent for some teacher members. These inquiry teams were typically organized around student populations such as English Language Learners, $9^{\text {th }}$ grade students, or special education students. In these situations, inquiry team membership included teachers from different grade levels and subject areas. In this scenario, the only free time to meet was during lunch or outside the school day. Also, the diversity of team membership made it difficult to identify strategies to test across different subject areas or grade levels. As a result, rather than working in tandem to refine an instructional strategy, each teacher was left to develop and test a strategy in isolation. 
Although challenging to implement, the need for cross-subject, cross-grade dialogue heard at many schools does suggest that the existing school structures may need formal adjustment to help teachers better support student populations with significant learning needs. One study school realized this need early in the school year and, with a faculty vote, established a dedicated weekly inquiry time for all teacher teams in the building. Under this new structure, teacher inquiry became a formal part of the school calendar.

\section{Schools are more effective in establishing a core inquiry team when leveraging existing work groups. The responsibility for reviewing the products and learning points of teacher inquiry teams were extended to two existing decision-making bodies: the school instructional cabinet and/or the original inquiry team first established to pilot the inquiry work for the school.}

The instructional cabinet is a key decisionmaking body on matters of curriculum, instruction, improvement goals, and resource allocation. To include the inquiry work, its current membership of administrators and coaches was expanded to include representatives from each teacher inquiry team. In this context, the findings of all teacher inquiry teams were then woven into a broader reflective dialogue about school goals and performance. In turn, teacher representatives gained a broader understanding of how their inquiry work might inform school-level improvement, such as adjustments to the instructional program, professional development, or the allocation of resources.

To support the engagement of more faculty in inquiry, schools also leveraged the original inquiry team of administrators and teachers into a new core inquiry team for the school. This school-level team included members with strong knowledge and experience conducting inquiry and who also served on the school's instructional cabinet. As part of its transformation, the principal expanded the original inquiry team to include representatives from each teacher team. The core inquiry team was responsible for building the capacity of teacher teams to conduct inquiry. In this role, core team members sometimes served as facilitators for the individual teacher teams, providing guidance about key decision points in the process and gathering information and resources to support teachers' work. The core inquiry team also scanned for opportunities to leverage the strengths of individual teacher teams by collecting process tools, strategies, or assessments that would benefit others in the school.

Summary. The experience of study schools suggests that the leveraging of existing teacher groups or decision-making bodies more efficiently facilitated the inquiry work than did implementing new team structures. It facilitated the logistics of team meetings and drew upon the shared knowledge base and common responsibilities already held by teachers and administrators. To establish teacher teams, principals used existing grade level, subject/department, or special student services teams. To establish a core inquiry team, principals relied upon the instructional cabinet or the original team that had piloted the inquiry process for the school. 


\section{Time for Collaborative Inquiry}

\section{Dedicated, protected time for collaborative inquiry is essential.}

A fundamental condition supporting teacher engagement in collaborative inquiry is the existence of dedicated and protected time. To be effective, school leaders must allocate time for teachers to engage in two distinct, but interdependent activities. These include

- Time for teachers to work with selected inquiry students to diagnose their learning needs and test instructional strategies, and

- Time for teachers to meet as a team to analyze data, reflect on the conditions of teaching and learning, develop instructional strategies, and identify needed changes in school instructional systems.

Study schools that allocated and protected time for teachers to engage in these two essential activities reported greater benefits from the inquiry work for their students and the school. These schools provide examples of how school leaders are able to leverage existing program resources and schedule team meeting times to support these two core activities of inquiry.

School leaders find adequate time before, during, or after the school day for teachers to work with inquiry students. Finding time for teachers to work with inquiry students was not a problem for study schools. Most schools had well established extended-day programs that provided students with tutoring either before or after school. In elementary schools and some high schools, teachers simply worked with their inquiry students through these existing support programs. In most cases inquiry students were already enrolled in tutoring because their achievement levels were in the bottom third of the class. Teachers also found time to work with inquiry students during the school day. Since teachers chose inquiry students from within their current classes, some teachers used time during the day to work with them one-on-one or in small groups. Teachers considered working with students during the day to be part of their broader effort to differentiate instruction for individual students and groups of students. This approach was particularly useful to teachers who were supporting five or more inquiry students.

School leaders find time for teacher teams by leveraging the established meeting schedule or by altering the school schedule to identify a dedicated time for inquiry team meetings. At the elementary level, a common practice was for the principal to allocate one or two teacher preparation periods each month for teacher inquiry discussions. At the elementary level, this was an effective strategy because teachers in the same grade typically have the same schedule. Teachers rotated the meeting focus between grade-level planning and the inquiry work. In one school that was particularly effective in supporting inquiry school-wide, the principal called upon all assistant principals, coaches, and teachers to push logistical and routine work to email and other communication channels so that face-to-face conversations focused on improving teaching and learning. This also supported a new 10-minute allocation during monthly faculty conferences for two teacher 
inquiry teams to present their progress to the full faculty.

Once allocated, most elementary school principals protected teacher inquiry time. Their commitment firmed up over the school year as teacher teams reported evidence of student progress and identified strategies that helped meet student needs. Protected time was not a guarantee, however. In schools where principals did not dedicate time, inquiry meetings were brief and unstructured, and teachers met infrequently. The productivity of their team inquiry work was low. In schools where the principal failed to protect allocated time for teachers to meet, the collaborative dimension of inquiry was lost.

At the secondary level, strategies for finding time in the school schedule for teacher inquiry were more challenging. First, as larger, more complex organizations, identifying a common time for teachers to meet by subject, course, or grade was not always possible. Second, the focus of many secondary school inquiry teams cut across subjects, grade levels, and student subgroups, $9^{\text {th }}$ grade newcomers being an example. Because inquiry was implemented after the start of the school year, teachers typically chose to meet as an inquiry team before or after school or during lunch period. In study schools, most teams in this situation were able to find time during the school day when most members were available. In one large high school, this was not possible. To accommodate teacher inquiry teams, dedicated time in the school schedule proved to be necessary. The principal and union representative sponsored a successful faculty vote to extend the school day once a week to support teacher inquiry teams.
Summary. To support collaborative inquiry, principals must identify teacher inquiry teams and also a core inquiry team in the school. Leveraging existing teacher work groups and school-level decision-making bodies facilitated the introduction of collaborative inquiry. 
Teacher Use of Student Data to Inform Instruction

\section{Inquiry strengthens teacher understanding and use of student assessments and performance data to improve their instructional decision-making.}

The vast majority of teachers interviewed expressed the view that the collaborative inquiry process enhanced their use of data to inform classroom practice. The general view was that the broad engagement of teachers in collaborative inquiry created a more intensive school-wide focus on the use and interpretation of student data from multiple sources. Here, one teacher reflected on the pervasive role of data in the school this year.

It is so interesting to see the great extent that our school is involved with data. We were like that before, but it was really pushed this year with inquiry. Never in my life of teaching have we focused on data as much as we have over this past year. We never before looked at the students in the way that we are looking at them now. It's amazing.

The increased centrality of data was reported even in schools where teachers were already reviewing formative and summative assessment data on a routine basis.

Almost all teachers reported an expanded knowledge of assessments through their inquiry work. Particularly at the elementary level, teachers reported a steady flow of information from many sources to assess and monitor the progress of inquiry students and their class. The inquiry work provided an important new opportunity to integrate and examine these data to support the inquiry students. Teachers reported regular use of the ARIS system to search for patterns in attendance, performance, and other background information for their students experiencing difficulties. They reported routine use of student performance data from formative and periodic assessments, and recent student work was a common reference point during inquiry meetings. During interviews, teachers expressed increased confidence in using student data to inform their instructional decisions, a change in attitude that they attributed to the inquiry work.

\section{Collaborative inquiry helps teachers build an evidence-oriented professional community within the school. The} dominant view among teachers and administrators, strongest in elementary schools, was that collaborative inquiry was an important new process in the school. The inquiry work enabled teachers to use data more effectively to make informed decisions about their students' learning needs and to adjust their instructional practice. One teacher characterized the contributions of inquiry as ensuring that their data-informed decision-making process was ongoing, not periodic, and connected to instructional choices. She explained:

It is important for teachers to know that collaborative inquiry works. It helps because you are focused on this particular group of students who are lacking in a particular skill, and when done correctly, it works. You keep your data. You are making sure that you are implementing the strategies that can help the students improve. When you see it is not working, you get other ideas so that it can work. ... It is different in terms of 
keeping the data. It use to be about marking periods where you look at the students and their weaknesses and what they need to improve at the beginning of the school year, in the middle of the year and towards the end. But with inquiry it is more ongoing and you are constantly looking at whether the students are getting it and how you can help them. It is more a constant and ongoing process.

As this description underscores, inquiry provided schools with a new organizational routine to help teachers make sense of the volume of data available to schools and help teachers use data to guide their instructional choices. The intensive work with inquiry students and examination of connections between student learning and current instructional practice contributed to this growth.

For some teachers, the inquiry work has changed their general opinion about the utility of data and the routines required to collect and analyze data for their teaching. In the context of inquiry, the meaning and value of data became more apparent to teachers. They credited the inquiry process with "changing” their mind about the value of gathering and interpreting data. These teachers realized that assessment data from running records, the Early Childhood Literary Assessment System (ECLAS), and Acuity assessments, for example, could provide specific information about student learning, and that this was more valuable for instructional decisions than the general impressions they had relied upon previously. These teachers were selfdeclared converts and avid consumers of student performance data.

Some teachers reported making new connections between their instructional practice and their analysis of student learning needs. They also acknowledged valuing the process of collecting and examining student data. One teacher explained that she now views gathering data as useful "preparation" - not "paperwork" to guide teacher conversation during inquiry team meetings. Another teacher described how participation in inquiry also changed her perspective on the value of data and record keeping:

I have learned that student data can be useful. Most of the time, we all think that data is really time-consuming and that it takes a lot of effort to keep up with it. But in the end, we see that it is really valuable. If I spend just those 15 minutes of prep time during the morning to enter student data, it really makes a big difference in the end because I have something that I can bring to the inquiry team and show them what works or does not work for the students.

\section{Collaborative inquiry helps some teachers} develop basic knowledge about different data sources. These teachers reported that prior to participating in the inquiry process they were unfamiliar or uncomfortable with data. Some teachers referred to student information generically as "the numbers." Teachers credited the inquiry process with helping them gain basic understanding about different types of performance data and a new perspective on how these data might inform their classroom practice. Explained one teacher:
Absolutely, inquiry has enhanced my use of data. I did not know anything about formative assessment and the value of diagnostics until inquiry. And now my assessments are so good.

The regular convening of teacher inquiry teams along with dedicated time to work 
with inquiry students represented an important new opportunity—what one teacher described as "being given a space to learn more about data." For some teachers, this meant finally being able to participate in and contribute to an ongoing dialogue in the school that they previously had felt excluded from because of their limited knowledge and experience. This was important to teachers because it deepened their understanding of the specific learning needs of their inquiry students and enabled them to become active participants in inquiry team conversations.

\section{Through inquiry, teachers develop new tools for integrating information from multiple sources, which they use themselves and with other teachers.}

Teachers credited inquiry with helping them develop fundamental knowledge about the management and use of student performance data. Others reported developing new routines for collecting student performance data from their students periodically. For example, teachers developed portfolios for their inquiry students that included student work from different points in the school year, assessment data reports, and instructional materials. Teachers developed "snapshots" or "profiles" of individual student performance history in a table format that merged relevant background information, notes on discussions with family and other teachers, and longitudinal performance data. Teachers developed routines for organizing and presenting student data through their work with individual inquiry students. This helped teachers analyze student needs and use that insight to inform their instructional choices. Two teachers explained how inquiry contributed to this new skill in data management:

Inquiry helped me become more organized. I was one of those teachers who just knew things off the top of my head. The inquiry team shows you how to keep the data and be able to point to it. Yes, ECLAS, but also creating data sheets to see things at a glance, building my own kind of data reports.

Through inquiry I am gathering my kids' work and creating a little portfolio for them. I am able to look back to where they were in the beginning to see how they improved up to this point. What we are doing with data now, we did not do before. Now it is an ongoing basisevery week. Before we only used data in the beginning and middle of the school year.

\section{Teachers report stronger connections between their instructional decision- making and their analysis of student data.} Teachers attributed this growth to the structure of the inquiry process itself, which asked each teacher to use data at different decision points in their instructional planning. Specifically, the process raised teacher awareness of the particular needs of individual students and facilitated an evaluation of the effectiveness of an instructional response. By focusing on an individual student or small group of inquiry students instead of the whole class, the inquiry process helped teachers make clear, specific connections between their teaching and evidence of student learning. One teacher described how inquiry helped her assess the effectiveness of her instructional choices:

Collaborative inquiry has definitely added to my teaching. I am constantly looking at the data. It has helped me as a teacher because I can reflect on my teaching and instead of saying, "Oh, that did not work." I can say, "Oh, that is why it did not work." I can prove it to 
myself because now I have the evidence to back up my opinion.

Summary. Collaborative inquiry provided schools a new organizational routine that helped teachers understand and use student background and performance information for their instructional decision-making. It helped teachers with different levels of familiarity and experience using student data to adjust their practice. Some teachers felt they developed basic knowledge about the data sources available to schools. The inquiry work helped other teachers see the value of analyzing student data to plan their lessons, particularly those who were once apprehensive about data or questioned the value of time spent recording and integrating data from multiple sources over time. In this regard, teachers developed new tools for integrating data, which came from their work with a small group of inquiry students. Over the course of the school year, as student work improved, teachers reported seeing stronger connections between their ability to analyze data and their instructional decisions. Overall, teachers reported developing routines for using data and a personal belief that the review of student data was an important step in their planning process. 


\section{Collaborative Inquiry as Ongoing Professional Development}

\section{Collaborative inquiry is an effective form of on-the-job professional development for teachers and can lead to the identification of school-wide professional development needs.}

Improving student achievement requires parallel investments in building teacher capacity. Teachers need professional opportunities to develop the necessary knowledge, skills, and dispositions to meet the needs of students who are struggling in their classrooms. In public education, the most common models of teacher professional development include formal training, classroom observation and feedback, mentoring, study groups, action research, and participation in a school improvement process. These models are most effective when they are guided by a clear purpose and specific goals, are designed as an ongoing process embedded in teachers' professional work lives, and consider the organizational conditions needed to support the new practices (Guskey, 2000).

Collaborative inquiry has the potential to serve as a powerful source of professional development. Both the purpose and process of collaborative inquiry draw upon multiple models of professional development. As described earlier, inquiry is a form of action research as teachers work in their classrooms and in concert with others to explore and address specific learning needs.
The work of teacher teams constitutes a school improvement process when the inquiry work is aligned with school performance goals and team findings are used to inform school-level decisionmaking. In addition, the findings and products of teacher inquiry can inform formal training needs so that faculty can acquire new knowledge and skills.

Furthermore, the design of collaborative inquiry itself reflects key characteristics of effective professional development. The inquiry process is guided by a set of specific learning goals for a small set of inquiry students, which ensures that the capacities teachers are developing through the inquiry work are aligned with the knowledge and skills needed to support students experiencing difficulties in the classroom. It is also designed as an ongoing learning process that spans the course of the school year and scaffolds teacher investigations of student learning, from the diagnoses of student needs to the identification of effective strategies. The process can be formally integrated with the professional work of teaching and learning in the school by integrating inquiry work with existing work groups, allocating dedicated time, and creating clear connections between inquiry and school improvement goals. Finally, collaborative inquiry is a systemic process because it calls attention to the structural supports required to implement team findings. Attention to putting supportive school conditions in place can help ensure that the new knowledge and practices that teachers acquire through inquiry are effective and sustainable.

Given the strong alignment between the design of collaborative inquiry and the characteristics of effective professional development, it is not surprising that teachers and administrators across study 
schools viewed inquiry as a source of professional growth for themselves and others. Most administrators believed strongly that inquiry was expanding teacher capacity to support students who were struggling, through deeper knowledge of student needs, awareness of effective strategies, or a strengthening of teacher professional culture. One principal's view expressed this widespread belief:

I believe that inquiry provides teachers with an opportunity to develop their craft. It gives them a chance to really get to know their students and to really dig deeper into what is the root cause affecting their students' achievement. I think that all of these things affect how the school is doing as a whole. It is important that teachers develop a deeper understanding about the students as a whole and individually in order to know how to effectively address problems in the school and improve it.

Teachers and administrators believed collaborative inquiry was an effective form of job-embedded professional development in two ways:

- Through inquiry, individual teachers reported developing new knowledge, skills, and relationships that enhanced their teaching.

- The inquiry team findings informed and supported school-based professional development needs.

The vast majority of teachers felt they had grown professionally through the inquiry work at an individual level. Schools with a core inquiry group with decision-making authority were able to use the inquiry work to inform the professional development needs of the school.

\section{Collaborative inquiry can be an effective} form of on-the-job professional development. As described earlier, most principals were able to integrate the collaborative inquiry process into the daily work life of teachers. This occurred by leveraging existing work groups and allocating time for inquiry. Teachers were able to work closely with selected inquiry students to diagnose and address persistent problems of teaching and learning in their classrooms. In most schools, teachers were able to meet as an inquiry team because principals allocated time for collaborative inquiry in the school schedule and protected that time throughout the school year.

When asked about the value of collaborative inquiry to themselves as individuals, teachers often characterized the inquiry work as an on-going professional development activity that carried through the school year. In schools where teachers met regularly with inquiry students and as a team, teachers felt collaborative inquiry was a source of on-the-job learning. A teacher explained this view:

As a teacher I love going to workshops and being with other teachers. The inquiry work was like having in-house professional development, right here in the school, for each other. It is a way to help students, improve the learning process, and make a better experience for the kids. It is definitely a resource.

Teachers valued their inquiry team as a venue for professional development. It provided a personalized setting for their learning. Teachers characterized team meetings as "more individualized," and "more one-on-one," compared with large workshop settings. Teachers felt inquiry work provided new opportunities to improve 
their understanding. Said one teacher whose knowledge of assessments expanded dramatically through the inquiry work: "I can ask a lot of basic questions about the assessments and all the data we can access now. We are all learning." And since the inquiry work was oriented towards helping teachers take action to improve student performance, teachers valued the emphasis on learning and doing. "I'm using what I learn in inquiry right now. It's not theoretical or some plan for the future," explained one teacher. Teachers felt they were engaged in important work and were learning through the process. This made the process productive and enjoyable for both teachers and administrators. One Data Specialist facilitating the work of all teacher inquiry teams shared this: "Our inquiry conversations were so interesting that it did not feel like I was working."

Teachers felt their knowledge and skills were developing through the inquiry work, suggesting that the process was an effective form of embedded professional development. Most teachers reported personal growth in three areas:

- Enhanced knowledge and use of student data;

- Expanded repertoire of effective instructional responses to meet specific student needs; and

- Increased knowledge of and attention to specific student populations in their classroom.

Teachers attributed their personal growth to the key features of the inquiry process itself - that is, working closely with inquiry students to improve their learning and engaging in conversation with other teachers about their practice and developing strategies to test.

Teachers felt participation in an inquiry process expanded their understanding and use of student background and performance data. As described earlier, teachers felt the inquiry process expanded their knowledge and use of data for instructional decisionmaking. Teacher growth through inquiry was accelerated by related school initiatives and workshops that introduced teachers to new data resources available through the Department. Almost all teachers had recently participated in ARIS training and were aware of the student background and performance information available; a few schools were also just learning the Teachers College Reading and Writing Project AssessmentPro. Others at the elementary level had attended workshops introducing formative and predictive assessments (e.g., Acuity, ECLAS, ITAs, and running records). In this context, inquiry provided a much needed venue for teachers to refine their collective understanding of the purpose and features of the new assessments and data systems. One teacher explained this process:

Through inquiry, I have refocused on my kids and I am learning where they are. This year is brand new to me. I had to find core reasons why my inquiry kids are not reading, by using data. And I had to learn the core foundations of reading. ... I now break everything down. The data helped train my eye to spot the problem. Before, I was stuck trying to help kids. I was overwhelmed. The inquiry process helped me to break down the child's problems in reading and to prioritize.

It also provided an important opportunity to learn to apply that new knowledge to meet 
the particular learning needs of inquiry students. Through the selection, administration, and interpretation of assessments, inquiry deepened teachers' understanding of how data can inform instruction.

As a source of professional development, teachers also felt participation in the inquiry work had expanded their knowledge and use of effective instructional practices. Most teacher teams were able to identify specific teaching strategies that improved the learning of their inquiry students. In some cases, these were new strategies that teachers had not used before. In other cases, teachers learned to better diagnose a student's area of need, which refined their instructional choices for different groups of students. One teacher explained how she learned two new instructional strategies through the inquiry work and how each helped her meet the different learning needs of the inquiry students.

Because of inquiry this year, I am in tune with children as individual learners and how to adjust my instruction. Before inquiry I would have said, "I know they can do it, but I just don't know how to get them there.” Now I know. Even if you have two kids and they both are a level $\mathrm{D}$ in reading, their issues are not the same. The data helps you identify specifically where each was weak. As a team, we developed different strategies to use with our students - one for building vocabulary and another for sight words based on student weaknesses — and they worked. Having input from other 1st grade teachers, knowing that we are working together, I can say I know I can help these students. This is a real outcome of the inquiry process.
Teachers reported integrating instructional strategies learned through inquiry into their work with the whole class so that it became part of their instructional repertoire. Some teachers were learning to differentiate their instruction and through inquiry work were using their learning to support small groups of students with the same learning need. With better diagnoses through new sources of assessment data and an expanded repertoire of instructional strategies, a number of teachers felt they were able to differentiate their instruction for individuals and groups of students.

Finally, teachers felt that the inquiry work greatly enhanced their awareness and understanding of a specific population of students struggling in the building. This was an important opportunity because in many schools these students had been underserved due to a lack of internal expertise or time for close study, or other school issues took precedence. These students were typically English Language Learners or newcomers to the United States. The introduction of collaborative inquiry school-wide, according to a few principals, was a much needed opportunity for teachers to work together to understand and support a population of students that was growing in their building.

We have been experiencing a change in our student population in recent years that is growing. Inquiry is valuable to us because it is helping us get to know our students. We are spending time with them, learning about their home life, about their past school history, and trying to build on their strengths. We desperately need instructional strategies and whole programs that are sensitive to their needs. A number of inquiry teams are focused in this way. 
In this context, teachers began to expand their understanding of their students' educational, cultural, and social background. One teacher whose inquiry team focused on better supporting ELL students' reading comprehension described her growing commitment to support this student population in her classroom.

Inquiry has definitely improved my own practice of reflection. Inquiry encouraged me to seek out strategies and other teachers. It helped me look at the ELL students in a new way. I am better at educating them now. I cannot ignore them anymore because I don't know what to do. Now I change my lessons specifically to keep them in mind. Now I feel like I can help them.

\section{Collaborative inquiry informs school- wide professional development needs.} This took place in two ways. First, during the school year, administration and core inquiry members encouraged teams to share their inquiry process, team materials, and findings through existing professional development mechanisms within the school. One principal explained the new connection this way: "Most professional development is in-house and it just comes out of questions from the inquiry meetings." In some schools, teams were mindful that the outcomes of their inquiry work might be shared with other teams or across the school. One teacher described this orientation:

In the ELA inquiry group, the things discussed often translate into the professional development. We discuss this. We try to identify teaching strategies and then share it in the professional development period with faculty. We focus on how to use it for other content areas ... how to devise math strategies, for example. It helps.
Administrators and teachers leveraged existing professional development routines in their schools to share the process and outcomes of the inquiry work during the school year. These included monthly faculty conferences, periodic school-wide professional development days, learning walks, and teacher intervisitation/classroom observation. Of note, teachers tended to frame participation in these professional development activities as examples of teacher leadership within their school. A description of how the inquiry work informed each of these development activities follows.

- Faculty Conference Presentations. Teacher teams rotated presenting their inquiry process and insights to other teacher teams during monthly faculty meetings. As a faculty, teachers discussed team insights and connections across teams. Discussions promoted reflection about the consistency of assessment administration and the interpretation of results across classrooms. It also led to reflections on the level of curricular coherence across grades in terms of teacher emphasis on particular core concepts and skills and the prominence of particular instructional strategies.

- School Professional Development Days. Individual teachers, groups of teachers, or inquiry teams submitted proposals for teacher-led workshops and presentations for a school professional development day. Not only did more teachers submit workshop proposals, the topics increasingly were drawn from the inquiry work, according to administrators. Topics focused on the particular stages of the inquiry process (e.g., examining student work or 
monitoring sudden progress); insights about student learning or teaching practice in a particular skill or subject area, or for specific student populations; assessments developed; instructional strategies tested and student results; and a sharing of materials.

- Learning Walks. As a collaborative reflection exercise, teachers and administrators in groups conducted short visits to multiple classrooms to observe the instructional strategies or assessments of inquiry in action. Observations of the strengths and weaknesses of practices as well as anything else of note, were discussed during various school committee or teacher inquiry team meetings, or shared through team leaders during core inquiry meetings. In one school, members of the core team also collected materials and student work to share with faculty.

- Classroom Observations or Teacher Intervisitation. As part of their inquiry process, teacher inquiry teams engaged in two types of classroom observations in which teachers observed other teachers. One purpose focused on the demonstration of specific classroom practices for teachers seeking assistance with implementation. Examples included the administration of an assessment, use of a particular instructional strategy, or use of small group work to differentiate instruction. Other classroom observations focused on documenting the conditions of teaching and learning related to a specific concept or skill focus of inquiry. Within an inquiry team, teachers visited each other's classrooms to note the content, teaching strategies, and student response, among other topics. Teachers developed templates to guide their observation and structure notes - a practice sometimes referred to as low-inference transcripts. Together they reviewed their notes to identify the strengths and weaknesses of the curriculum in use, diagnose areas of need for inquiry students, and brainstorm potential instructional responses.

These brief descriptions present a compilation of the professional development opportunities that were informed by inquiry across study schools. Together they illustrate how the knowledge gained from inquiry can become shared across the school.

Second, principals used the inquiry work to identify formal professional development needs for teachers and administrators school-wide. These were part of a set of broader decisions to adjust school programs identified through the inquiry work. One teacher described a series of changes to the instructional program of her school through the inquiry work:

The first year I was only working with ELL students and we learned that retelling was helpful and now that strategy is used with the whole school. Also with special education, we found out that in order to improve fluency, they needed to be able to decode. That was a very helpful finding not just for special education, but also for the rest of the students. Inquiry work is a lot of work but with benefits. And by working in teams the professional development community is so powerful.

One elementary school in the study offers a rich example of how insights from the inquiry work informed school-wide professional development. The principal communicated throughout the year that the goal of inquiry was to strengthen the school as a whole. Teacher descriptions of the 
purpose of inquiry reflected these strong expectations. Said one teacher: "Even though we are working closely with targeted groups, the idea is to make system-wide changes that help children.” In this context, the core inquiry team was an active decision-making body for the school. Its members constantly reflected on the insights from inquiry over the course of the school year and tested their observations with other teachers. For example, when one inquiry team identified inconsistent use of the running records assessment to gauge reading progress, all teams were asked to reflect on this particular aspect of their practice. When variation was noted across the school, professional development was scheduled for faculty. Inquiry enabled the entire school community to take ownership of this problem of practice and to support the development of all teachers. The following are additional examples of adjustments made to the school's instructional program that emerged from the inquiry work. Each adjustment led to parallel investments in professional development at the school. These included:

- Adopting a new reading assessment;

- Standardizing the administration and use of a common assessment;

- Adopting a new reading program;

- Promoting individual and small group instruction;

- Developing and testing strategies for teaching writing across the curriculum; and

- Sharing strategies for work with ELL students and with special education students across the curriculum.
In this school, where the inquiry work functioned at a more advanced level, the principal stressed the importance of ensuring that teachers had access to appropriate training when larger changes were made in the school. In some cases, external staff developers were relied upon, but in other cases, professional development was delivered internally by coaches and teachers. This took place at the start of the school year, during professional development days, or through grade meetings. This school was an exception in the study. When asked in May if the inquiry work had informed broader changes in their schools, many principals responded "not yet" due to the newness of the process. Said one:

We are not yet in that stage of inquiry. It will happen at some point. We are working towards that goal. This is our first year where inquiry is school-wide. We are just getting our feet wet.

As a step in that direction, principals planned a reflection event for all teachers at the close of the school year to discuss the inquiry work. During this meeting, they planned to take stock of the experiences and learning of all teacher inquiry teams.

Summary. Teachers and administrators believe collaborative inquiry is an effective form of job-embedded professional development in two ways. Through their inquiry work, teachers reported learning to use data to diagnose the specific learning needs of students, use effective instructional strategies, and develop a deeper understanding and commitment to underserved student populations in their classroom. Collaborative inquiry also informs school-wide professional development needs. Through existing professional development mechanisms 
within the school, inquiry teams and individual teachers shared their inquiry process, team materials, and findings with others. Principals used the inquiry work to identify professional development needs for all teachers and administrators. The topics of these workshops reflected decisions to adjust the school instructional program based on findings from teachers' inquiry work. 
Connecting the Inquiry Work to School Improvement Goals

\section{Collaborative inquiry is more focused and productive for teachers when aligned with school improvement goals, particularly when teachers are engaged in the goal-setting process.}

When a high proportion of faculty is engaged in collaborative inquiry, it has the potential to help the school make progress in achieving its annual performance goals and to sustain that improvement over time. In study schools where teacher inquiry was more focused and productive, teachers reported seeing specific connections between the inquiry work and particular school improvement goals. These study schools engaged in the following practices:

- The principal set clear expectations that collaborative inquiry should contribute to school performance goals and engaged teachers in a goal-setting process.

- Teacher inquiry across the school was supported by common tools aligned with school performance goals.

- The principal strategically used core inquiry meetings to monitor and reflect on the progress of teacher inquiry teams in relation to school goals.

The principal sets clear expectations that the work of collaborative inquiry should contribute to school performance goals. A common strategy was to engage faculty in a goal-setting process to launch inquiry school-wide. In some schools this occurred before the start of the school year; in others it occurred on a professional development day sometime in the fall. It included an introduction to the inquiry process itself and a description of teacher teams being planned.

Importantly, teachers were engaged in a goal-setting process in which together they reviewed and discussed multiple sources of data that informed the annual school-level performance goals, such as state and periodic assessments and other student information. They also examined data by grade, subject, and specific student subpopulations to pinpoint areas of weakness that needed attention. Teacher inquiry teams then developed working performance targets for their grade or subject area, with individual teachers developing goals for their class.

Adjustments to the inquiry goals took place as teacher teams selected inquiry students, assessed student needs, and examined the conditions of teaching and learning around the chosen skill area. These adjustments remained aligned with school performance goals because teachers had developed a strong awareness and understanding of broader grade-level and school-wide performance trends. Over the course of the school year, the experience of the goalsetting process continued to guide teacher inquiry teams as they moved through multiple cycles of inquiry. One assistant principal explained:

As a school, we specifically are targeting reading comprehension. Subskills vary by grade level. A core goal is to help students independently monitor for meaning and activate strategies. Every student in the school is expected to make 
one year's worth of progress. For grade 3 , for example, inquiry students are expected to make one and a half years' worth of progress, 4-5 levels forward on the Teachers College assessment. We picked 2-3 kids in the bottom third of each class. We monitor their progress through reading level movement.

In schools where principals launched inquiry with a goal-setting process, teachers were able to provide specific explanations of how the inquiry work contributed to school improvement goals along with evidence of student growth. Here, one teacher explained the progress of her team's inquiry work:

The 4th grade inquiry team's goal is to improve vocabulary and to get our ELL students and those below grade level up to grade level. We want to increase vocabulary and teach students to use context cues. We work on vocabulary development with our inquiry students. In my class I also stretch it out to other students who need support as well. Our group's work impacts the school big time because a lot of the inquiry students have improved. They are now passing the English assessment and scoring a level 3. It is phenomenal and not just the struggling students, but also the ELL students.

In addition to student performance goals, a number of principals also used the inquiry work to emphasize the importance of teacher collaboration as a companion goal. When asked about the purpose of inquiry, teachers cited learning targets for their students as well as the importance of teachers working together, supporting each other, and developing effective strategies. In a few study schools, this was a formal school goal, but in most it was informal and simply emphasized by administration. Principals used the process to build or strengthen the professional culture of the school and stimulate teacher responsibility for student learning. A teacher in a school that was beginning to turn around after years of low performance explained the interdependence between goals for collaboration and improved student learning in her team's inquiry work.

With the opportunity for teachers to work together through inquiry, a goal for us is to strengthen our knowledge of effective strategies. We reflected a lot on the goals of the school for student achievement. I think a big goal for the school was also collaboration. This is a big school and there are not many opportunities for teachers to share what their strengths are. We do not have much experience working together to support all our students. This was new.

\section{Common school-level inquiry tools help teacher teams ensure that their ongoing inquiry work contributes to school performance goals. In a number of schools, teachers and administrators developed a variety of tools to support the inquiry work. Teachers often identified these tools during our interviews as material artifacts important to inquiry team conversations. These tools included elements that helped teachers remain mindful of how their inquiry work contributed to broader school goals. The following examples come from elementary schools.}

- Inquiry Process Protocols. At one school the core inquiry team developed a broad inquiry process tool to guide teacher team discussions. It included reflection points at each stage in the process for teachers to consider how their collective work was contributing to both grade and school goals. 
- Inquiry Documentation Tools. In another school, administration developed a documentation tool to help teachers track instructional decisions made during inquiry conversations. For each inquiry cycle, teachers noted the overarching school, grade, and class goals guiding their inquiry in the document header. The tool helped teachers track key information: baseline inquiry student performance, learning goals, descriptions of past teaching strategies, inquiry strategies tested, evidence of effectiveness, and student progress towards learning goals over time. Teachers reported drawing upon the information in this template during each meeting.

- $\quad$ Student Data Profile Templates. At a school in which the inquiry was focused on reading comprehension, administration developed a student data profile template to track evidence supporting their instructional decisions, which included school- and grade-level performance goals and supporting achievement data from available assessments. The template grid listed key assessments to guide teacher decision-making and entries for monitoring student performance every six weeks, along with written interpretations and new goals.

These tools are examples of how educators sought to embed the vision of the school in the material supports of the inquiry process. For a number of teachers, these tools helped manage their inquiry work with students. The tools also helped them maintain an awareness of how their evolving inquiry work was contributing to the broader performance goals of their grade level and their school.
The core inquiry team helps teachers remain mindful of connections between the work of individual teacher teams and overall progress in reaching school performance goals. This took place in schools where the principal included teachers in decisions about instructional improvement. The inquiry team leader who attended these core inquiry meetings reported discussion topics and team tasks that reinforced connections between teachers' inquiry work and school performance targets. Principals used the core inquiry team meetings to discuss the progress of each teacher team in terms of student learning and the efficacy of different instructional responses. During core inquiry team meetings, the principal and other administrators reviewed interim assessment data with teacher inquiry leaders to interpret new school and grade-level information in light of recent inquiry findings. These meetings also served as a venue for identifying areas of overlap across teacher teams to promote cross-team learning, such as when improving student reading comprehension or writing across the curriculum was a school goal. Inquiry teams making strong progress also shared tools, such as assessments, rubrics, or instructional strategies with other teams, a practice that reinforced common goals and their intention to work in concert.

Summary. A contributing factor to the focus and productivity of the inquiry work was its alignment with school improvement goals. Principals supported this alignment by engaging teachers in a goal-setting process to launch the inquiry work. Through a collective review of student performance at the school, grade, and subject level, teachers developed a shared understanding of the areas of learning that represented highleverage skills for improving student 
learning. As teacher teams delved into the details of analyzing the learning needs of students in their classrooms, school leaders helped teachers remain mindful of how their work was connected to school improvement goals. In consultation with teachers, school leaders promoted inquiry tools to help teams revisit the alignment of their work with the school goals at key decision-points in the inquiry process. To build cohesiveness and positive relations within each team, principals also emphasized the goal of collaboration. Finally, school leaders used the monthly core inquiry meetings to reflect with team leaders on their inquiry process and on their progress in reaching student learning targets. This school-wide view reinforced the interdependence of teacher inquiry teams in meeting the school performance goals. It also helped school leaders identify particular strategies, assessment approaches, and materials that could further strengthen the inquiry work throughout the school. 
Expectations and Policy Supports for Collaborative Inquiry

\section{Sustaining a cohesive central vision for student achievement and aligned policy supports is critical to deepening the inquiry work.}

Systemic restructuring initiatives are complex, ambitious reforms. By design, they are composed of multiple, interrelated initiatives, which can create two overarching challenges to their implementation. First, the key components of the initiative must be well aligned so that the messages of the reform are consistent and clear to school leaders and teachers. Second, key components should be accompanied by a set of resources and supports that align with the assistance needed by those charged with implementation, namely school leaders and teachers (Fullan, 1991).

Collaborative inquiry is one of many components in the larger restructuring initiative in New York City called Children First. The Department's initiative has been rolled out in phases, beginning with the restructuring of the central office to shift authority and system resources to schools, the establishment of accountability tools that set school performance goals and expectations for annual student progress, and the availability of technology and data resources and other assistance to support school leadership and improvements in teaching. Each year, the Department has adjusted these components and related resources to improve their utility to school leaders and teachers and to more closely align and integrate the components with one another. Recently, school engagement and support of collaborative inquiry, for example, has been integrated more explicitly with the Quality Review process. The use of collaborative inquiry also has been incorporated into the annual School Survey, which informs the school Progress Report. The capabilities of ARIS were expanded to include a feature called Inquiry Spaces that enables teacher teams to post their inquiry process, share materials, and communicate with other teams. The integration of these components aims to send clear and consistent expectations about student performance to schools. It also intends to increase the utility of available resources to support school efforts to meet those expectations.

\section{School leaders and teachers see strong alignment between the collaborative inquiry work and the Department's expectations for student performance.}

The expectations communicated by the Department reflect a steady focus on improving student performance and closing achievement gaps in each school, according to principals and teachers. They felt collaborative inquiry reinforced the Department's expectations because it draws attention to the learning needs of students who are struggling in their school and provides a process to support yearly improvement. Many teachers, particularly in elementary schools, perceived a balance of both pressure and support from the

Department in this regard. Said one teacher:

The last few years, the city is very clear in its thinking. They gave us time and resources to follow through on collaborative inquiry. There was not that history before. I have taught since 1992. The last 4-5 years, it has been clear and 
focused. The city made inquiry a priority.

Within schools, principals contributed to improvements in student performance by focusing teacher attention on groups of students who were struggling in the school. One principal summarized what many saw as an obvious alignment between external expectations and collaborative inquiry:

Inquiry is about improving student learning, just like everything else in the City. That is the focus. That is my goal as principal. That is our school goal. That is what the Department wants us to focus on. And I want teachers to focus on these struggling students in my school. Inquiry helps us do that. It is one of the best things the Department has done. It is making a difference.

This emphasis was not surprising since the annual performance review of each principal now takes into account school progress in meeting student performance targets each year. Principals made sure teachers knew well the school performance goals and were familiar with the key findings of the school's Progress Report and latest Quality Review. They also ensured that the focus of collaborative inquiry aligned with the school improvement goals for the year. In this respect, principal accountability helped ensure that messages from Department reached faculty, further contributing to a clear and consistent focus on student performance as a shared goal.

\section{The Achievement Reporting and} Innovation System (ARIS) and access to formative and periodic assessments are critical resources for the inquiry process. In terms of technology and data supports, almost all study schools reported wide use of these two resources and felt they were critical to teacher inquiry teams.

Teachers valued the accessibility and comprehensiveness of the ARIS data. Teachers felt ARIS was easy to use; many had attended formal training and teachers tended to serve as a resource for one another. Teachers valued ARIS for its content and the time it saved in gathering and preparing information for inquiry work. Access to student background and performance data was critical to the inquiry work. In the past teachers had pieced together this information through handwritten paper records or printouts from multiple data bases. They walked the school halls to have private conversations with students' former teachers. With ARIS, teachers were able to compile this data themselves in one sitting. For the first time, teachers had on-demand access to such comprehensive information about their students. One teacher explained:

This year is an amazing step forward because year one we were just getting to know everything and understand it. Everything now you can do like that [snaps fingers]. Back then, you had to wade through reams of ATS reports. Now you are supported by ARIS.

High school teachers, in particular, valued the ability to access student transcripts, course grades, attendance, and discipline notes from earlier grades, which had been difficult to retrieve from middle schools in past years. ARIS made this possible and relatively quick for teachers.

ARIS was a primary resource for supporting the inquiry work. Using data output from ARIS, teachers were able to look for patterns in student performance in their classroom to identify a student 
subpopulation whose learning needs became the focus of their inquiry. Information from ARIS and classroom observations helped teachers identify inquiry students they could work with over the course of the school year. Like many others, one teacher said she valued ARIS because it enabled the investigation of patterns in student behavior and learning on demand, explaining:

ARIS is tremendous. It helps target those children who need help. I can do it myself. I have all their resources. If you need to find data on a student, it is there for you. It can help you see connections in the school. If one child is quiet, and you do not hear from her, I think, Let me go see her records on ARIS.

The second data resource teachers believed critical to their inquiry was the array of periodic assessments available through the Department to monitor student learning and inform adjustments to their instruction. Teachers valued the quick turnaround of results, the ability to construct their own assessments, and the use of the item analysis, along with student work, to diagnose students learning needs and evaluate the effectiveness of their instructional strategies. At the elementary level, the Acuity ITAs and running records assessments (e.g., Fountas \& Pinnell) were highly valued.

While most teachers reported frequent use of ARIS, there were pockets of teachers who did not. These teachers were working in schools with limited computer resources. They also had limited personal experience working on computers and so continued to rely upon their Data Specialist or instructional coach to access student data. In some cases, participation on the inquiry team enabled some teachers to break through these barriers with the support of colleagues. But in at least one school, due to the limited resources and experiences with technology throughout the school, a stronger differentiated approach would be necessary. In this context, the inquiry process was weak in its impact.

\section{School leaders feel knowledgeable about the inquiry process due to their experience piloting it and from Department resources. The rollout of the collaborative inquiry process by the} Department was critical in this regard. Study schools had been engaged in the inquiry work for at least two years before expanding school-wide in the fall of 2009. Most schools supported only 1-2 inquiry teams in prior years, but members on these teams typically expanded or rotated, which increased the number of educators with direct experience. The Data Specialists, administrators, instructional coaches, and some teachers had direct experience with inquiry and could inform and support the new teacher inquiry teams in 2009-10. As one teacher noted, "The resources that have been the most valuable have been other teachers on the core team that have been through the process."

Drawing from their direct experience, these educators were able to demonstrate not only the key features of the process, but also how it could work in their particular school environment. They also provided templates and other material supports to launch the work school-wide. In a number of schools, past inquiry teams had presented their process and findings at the close of the school year, which served to familiarize teachers with inquiry. The formation of the core inquiry team also benefited from the previous inquiry work. Administrators and others were positioned to provide advice to teams and to monitor inquiry progress. 
External assistance to schools for implementing inquiry from their network appeared more limited in 2009-10 compared with prior years. Only Data Specialists new to their position attended network meetings where they learned about the process and received materials to support the launch of inquiry within their schools. As a result, most administrators relied upon materials from the prior year that they were familiar with and had found helpful. These included the Department's Inquiry Handbook, which described key phases of the inquiry process and provided illustrations of inquiry in action.

Veteran Data Specialists expressed disappointment in the lack of opportunity to participate in network meetings in 2009-10. They reported interest in learning about other configurations and approaches to the inquiry work. All principals, administrators, and teachers felt isolated in this regard. In fact, a few schools in this study would have benefited from feedback on the strengths and weaknesses of their inquiry configuration and advice about how it might be optimized. For example, in a couple of schools the core inquiry team conducted its own inquiry, parallel to teacher teams. This disturbed classes as they pulled out inquiry students and took teachers away from their grade teams. The core team concentrated its time on its own inquiry process rather than supporting teacher teams or reflecting on the insights of teacher inquiry to strengthen the school as a whole. Conversations with other schools or network leaders may have helped these schools fine-tune their configuration and better support inquiry in the school. In this regard, the Inquiry Spaces on ARIS could have provided a platform for schools to share information and advice about their inquiry work, but this feature of ARIS was not used in study schools in this regard. In addition, while administrators and teachers expressed interest in the inquiry work in other schools in general, none had taken steps to reach out to other schools. This may be due to the newness of inquiry this year to most teachers and to the limited time available to teachers and administrators to focus on school exchanges and other outreach.

\section{Teacher inquiry teams tend to rely upon internal expertise within their school to guide the inquiry work. There was a strong} sense of self-reliance across study schools. Teachers primarily relied upon expertise within their team or the school building for their inquiry work. This may have been due, in part, to budget cuts that had reduced or eliminated discretionary funds for hiring consultants or external staff developers in 2009-10. However, it may also have been due to the collaborative inquiry work itself. In encouraging responsibility for student learning through the inquiry work, teachers also were asserting self-reliance.

When teams did reach out for assistance, they did so by seeking out particular individuals with specific questions, and typically first went to other teachers. They often articulated a need for help identifying assessments to diagnose student learning needs, help with the interpretation of data, or help identifying instructional strategies. One teacher explained:

The biggest resources for me in the school and for inquiry are the other teachers. If we are having a lot of difficulty with a certain inquiry student, we can go up to other teachers and ask them for their input. This has been really helpful for me personally because I have had a lot of difficulties with the students and I still do. We teachers just really feed off each other. 
By looking among colleagues for expertise, teachers tended to identify other teachers in adjacent grades, their subject area, or other programs in the school who could inform their work. In some schools, teachers were also drawing upon existing materials and resources in their classrooms or the teacher resource room. In many cases, these sources were sufficient. But sometimes they were not. For example, some teams focused on a special student population, such as English Language Learners, but the resources available within the school were very limited or nonexistent. In these cases, the inquiry work was not productive; these teams needed access to external expertise to scaffold their learning about this student population and to provide access to appropriate assessments and research-based instructional strategies. In other cases, the reading program in the school was outdated; teachers did not have the knowledge of reading development, assessments, or instructional strategies to support their focus on reading comprehension.

Summary. School leaders and teachers saw strong alignment between the collaborative inquiry work and Department expectations for student performance. ARIS and ondemand assessments were important resources for the inquiry process and greatly enhanced teacher access to and use of student data. School leaders felt knowledgeable about the inquiry process due to their experience participating in the process in past years and from Department resources. Finally, teacher inquiry teams tended to rely upon internal expertise within their school to guide and inform the inquiry work. This was sufficient for many schools. However, the inquiry work in some schools was weakened by a lack of internal expertise and would have benefited from external support. 


\section{Conclusion}

Collaborative inquiry is a potentially powerful process for helping administrators and teachers use student data to improve instruction and raise student achievement. The experiences of educators reported by this study offer lessons for school leaders and district and state policymakers who are interested in using collaborative inquiry to stimulate professional learning communities within their schools and across a school system.

One set of insights centers on the leadership practice that can support teacher collaboration to improve student learning. A principal leadership style of shared decisionmaking was found to enhance teacher participation in collaborative inquiry. Teachers also benefit from opportunities to cultivate their own leadership practice, which grew from their inquiry work in their classrooms, during team meetings, and through actions to improve their school. Furthermore, the inquiry process was found to help schools tap and cultivate future school leaders from within their own faculty and administrative ranks.

Other insights highlight the benefits of collaborative inquiry in developing teacher capacities to support the learning needs of all students. As reported by teachers, the inquiry work was stimulating a qualitatively different conversation in the school. Teachers valued inquiry because it enabled them to take action together to address the immediate needs of students who were struggling in their classrooms. Importantly, teachers felt their understanding of student assessment data was improving through the inquiry work, as was their ability to use insights from data to inform their instructional choices. The reported growth by teachers suggests that the collaborative inquiry process is a source of ongoing jobembedded professional development for teachers. It also can inform broader professional development needs, which is critical to building teacher capacity to implement and support effective practices over time.

A final set of lessons calls attention to the conditions and supports that can facilitate broad participation in collaborative inquiry within a school. The leveraging of existing teacher groups to organize the inquiry work was more efficient than setting up new team structures. An essential condition is the allocation and protection of time for teachers to work regularly with inquiry students and to meet as a team. The inquiry work is more focused and productive when aligned with the school's annual improvement goals. Consistent expectations for improving student performance and access to comprehensive data systems and formative assessments were foundational tools that enabled teams to remain oriented towards evidence of student learning throughout the inquiry process.

As with any ambitious systemic reform initiative, continued attention to deepening and sustaining school engagement with collaborative inquiry, and related components of the larger Children First initiative, will be critical. Although collaborative inquiry is a prominent initiative of the Department, the ultimate goal is to integrate this process into the fabric of the schools as a new way of "doing business." This will take steady work over the course of many years on the part of policymakers, school leaders and teachers. The insights offered by educators in this study demonstrate some progress towards this final vision and suggest some steps schools can take in that direction. 


\section{References}

Anderson, S., \& Togneri, W. (2002). Beyond islands of excellence: What districts can do to improve instruction and achievement in all schools. Washington, DC: Learning First Alliance.

Boudett, K., City, E., \& Murnane, R. (Eds). (2005). Data wise: A step-by-step guide to using assessment results to improve teaching and learning. Cambridge, MA: Harvard Education Press.

Bryk, A., Sebring, P., Allensworth, E., Luppescu, S., \& Easton, J. (2010). Organizing schools for improvement: Lessons from Chicago. Chicago: The University of Chicago Press.

Carroll, T., Fulton, K., \& Doerr, H. (June, 2010). Team-up for $21^{\text {st }}$ century teaching and learning: What research and practice reveal about professional learning. Washington, DC: National Commission on Teaching and America's Future.

Center for Research on the Context of Teaching. (2002). Bay Area School Reform Collaborative: Phase one (1996-2001) evaluation. Stanford University: Author.

Cochran-Smith, M., \& Lytle, S. (1999). Relationships of knowledge and practice: Teacher learning in communities. Review of Educational Research in Education, 24, 249-305.

Copland, M.A. (2003). Leadership of inquiry: Building and sustaining capacity for school improvement. Educational Evaluation and Policy Analysis, 25(4), 375395.
Fullan, M. (1991). The new meaning of educational change. New York: Teachers College Press.

Gronn, P. (2003). Leaders' committees and meetings. The new work of educational leaders: Changing leadership practice in an era of school reform. Thousand Oaks, CA: Sage.

Guskey, T.R. (2000). Evaluating professional development. Thousand Oaks, CA: Corwin Press.

Harris, A., \& Muijs, D. (2004). Improving schools through teacher leadership. London: Open University Press.

Hightower, A., Knapp, M., Marsh, J., \& McLaughlin, M. ( 2002). School districts and instructional renewal (Critical issues in educational leadership). New York:

Teachers College Press.

Little, J.W., \& McLaughlin, M. (1993). Teachers' work: Individuals, colleagues, and contexts. Professional Development and Practice Series. New York: Teachers College Press.

Louis, K., Leithwood, K., Wahlstrom, K., \& Anderson, S. (2010). Investigating the links to improved student learning: Final report of research findings. Learning from Leadership Project. Center for Applied Research and Educational Improvement/University of Minnesota and Ontario Institute for Studies in Education/University of Toronto.

Mandinach, E., \& Honey, M. (Eds). (2008). Data-driven school improvement: Linking data and learning. New York: Economic Policy Institute and Teachers College Press. 
McLaughlin, M., \& Talbot, J. (2006). Building school-based teacher learning communities: Professional strategies to improve student achievement (Series on School Reform). New York: Teachers College Press.

New York City Department of Education. (2008). School leadership competencies and continuum. Retrieved on line March 15, 2010, at http://schools.nyc.gov/NR/ rdonlyres/4D9B9730-70A7-4EFB-B474C8FF670B45B8/0/NYCDOESchoolLeadership CompetencyContinuum.pdf.

Robinson, M., Kannapel, P., Gujarati, J., Williams, H., \& Oettinger, A. (2008, September). A formative study of the implementation of the inquiry team process in New York City public schools: 2007-08 findings. New York: Teachers College, Consortium for Policy Research in Education.

Vescio, V., Ross, D., \& Adams, A. (2008). A review of research on the impact of professional learning communities on teaching practice and student learning. Teaching and Teacher Education, 24, 80-91.

York-Barr, J., \& Duke, K. (2004). What do we know about teacher leadership? Findings from two decades of scholarship. Review of Educational Research, 74(3), 255-316.

\section{About the Author}

Marian A. Robinson is a Research Scientist with the Consortium for Policy Research in Education at Teachers College, Columbia University. In the past, her research with CPRE colleagues has examined a range of strategies for improving classroom practice from different levels of the education system, including district-based instructional coaching, state data tools for teachers and students, external comprehensive school reform, and state policy supports for teacher education. Previously, she worked as a program officer in the research unit of the US Department of Education and on special initiatives with national and local education reform organizations. 


\section{Nondiscrimination Statement}

The University of Pennsylvania values

diversity and seeks talented students, faculty and staff from diverse backgrounds. The University of Pennsylvania does not discriminate on the basis of race, color, sex, sexual orientation, gender identity, religion, creed, national or ethnic origin, citizenship status, age, disability, veteran status or any other legally protected class status in the administration of its admissions, financial aid, educational or athletic programs, or other University-administered programs or in its employment practices. Questions or complaints regarding this policy should be directed to the Executive Director of the Office of Affirmative Action and Equal Opportunity Programs, Sansom Place East, 3600 Chestnut Street, Suite 228, Philadelphia, PA 19104-6106; or (215) 8986993 (Voice) or (215) 898-7803 (TDD). 
